\title{
细菌纤维素基纳米生物材料在储能领域的应用
}

\author{
马丽娜 ${ }^{1}$, 石 川 $^{2}$, 赵 宁 $^{2}$, 毕志杰 ${ }^{2}$, 郭向欣 ${ }^{2}$, 黄玉东 ${ }^{3}$
}

(1. 青岛大学 化学化工学院, 青岛 266071; 2. 青岛大学 物理科学学院, 青岛 $266071 ; 3$. 哈尔滨工业大学 化工与 化学学院, 哈尔滨 150001)

摘 要: 细菌纤维素(Bacterial Cellulose, BC)是由微生物发酵获得的具有纳米尺寸的聚合物生物材料, 具有比表面积 大、机械强度高、持水能力强、化学稳定性好及环境友好等特质, 可用于制备三维纳米碳材料的前驱体或支撑其他 功能材料的柔性骨架。本文介绍了基于 $\mathrm{BC}$ 制备的各种碳纳米纤维(Carbon Nanofiber, CNF)及其复合材料, 包括掺杂 $\mathrm{CNF} 、 \mathrm{CNF} /$ 金属氧化物、 $\mathrm{CNF} /$ 导电聚合物等材料。描述了这些材料在超级电容器中的应用, 关注 $\mathrm{BC}$ 用于可弯曲 电极的设计和制备; 进一步阐述了当前 $\mathrm{BC}$ 应用于能源存储领域所面临的挑战和机遇, 并对其未来发展包括在高性 能二次电池方面的应用等进行了展望。

关 键 词: 细菌纤维素; 能源存储; 环境友好; 综述

中图分类号: TQ174 文献标识码: A

\section{Bacterial Cellulose Based Nano-biomaterials for Energy Storage Applications}

\author{
MA Li-Na ${ }^{1}$, SHI Chuan ${ }^{2}$, ZHAO Ning ${ }^{2}$, BI Zhi-Jie ${ }^{2}$, GUO Xiang-Xin ${ }^{2}$, HUANG Yu-Dong ${ }^{3}$
}

(1. College of Chemistry \& Chemical Engineering, Qingdao University, Qingdao 266071, China; 2. College of Physical Sciences, Qingdao University, Qingdao 266071, China; 3. School of Chemistry and Chemical Engineering, Harbin Institute of Technology, Harbin 150001, China)

\begin{abstract}
Bacterial cellulose (BC), an eco-friendly bio-product obtained from fermentation of various microorganism, consisting of the interconnected networks structure attracted widespread interest due to its unique physical properties, including the large specific surface area, remarkable mechanical strength, high water-holding ability, good chemical stability, and environmental benign material. These advantages enable $\mathrm{BC}$ to be applied to fabricate the highly versatile three-dimensional (3D) carbon nanomaterials, and tunable flexible scaffold to support other multifunctional materials. In this review, the production process of various carbon nanofibrous composites based on $\mathrm{BC}$, such as carbon nanofiber (CNF), doped CNF, CNF/metal oxide and CNF/conducting polymer, is presented. Their emerging applications in supercapacitors are illustrated, in particularly, the design of hybrid bendable electrodes based on BC substrate for flexible supercapacitor is highlighted. The challenges and opportunities in this fascinating area of designing functional nanomaterials and flexible electrode from BC for various energy storage are addressed. Moreover, the perspectives are given for the future development, including several significant kinds of study for applications in the rechargeable battery.
\end{abstract}

Key words: bacterial cellulose; energy storage; eco-friendly; review

收稿日期：2019-03-12; 收到修改稿日期：2019-05-17

基金项目: 国家自然科学基金(51532002，51771222，2180050937); 中国博士后基金(2018M632617); 山东省自然科学基金 (ZR201702180185)

National Natural Science Foundation of China (51532002, 51771222, 2180050937); China Postdoctoral Foundation (2018M632617); Shandong Provincial Natural Science Foundation (ZR201702180185)

作者简介: 马丽娜(1988-), 女，副教授. E-mail: malina@qdu.edu.cn MA Li-Na (1988-), female, associate professor. E-mail: malina@qdu.edu.cn

通讯作者: 郭向欣, 教授. E-mail: xxguo@qdu.edu.cn GUO Xiang-Xin, professor. E-mail: xxguo@qdu.edu.cn 
纤维素是由 $\mathrm{D}$-葡萄糖单元通过 $(1 \rightarrow 4) \beta$ 糖苷连 接组成的可再生生物聚合物, 其原料丰富、分布极 为广泛，在能源、材料、化工等领域有着广泛的应 用 ${ }^{[1]}$ 。细菌纤维素 (Bacterial Cellulose, $\mathrm{BC}$ ) 是一类极 其重要的纤维素, 由木醋杆菌、根瘤菌、大肠杆菌 等微生物细菌发酵而成, 制备成本低并可规模化生 产(图 1(a) $)^{[2] 。 B C}$ 虽与植物纤维素具有相同的化学 结构 ${ }^{[3]}$, 却具备独特的优点: 1) 高比表面积和孔隙 率。 $\mathrm{BC}$ 是由直径为 10 100 $\mathrm{nm}$ 的超精细纳米纤维 组成的 3D 网络结构(图 1(b e e) $)^{[4]}$, 直径比植物纤维 素纤维 $(\sim 10 \mu \mathrm{m})$ 小 2 个数量级, 有利于其他物质的 负载; 2) 高纯度和结晶度。BC 的纤维素含量几乎为 $100 \%$, 而植物纤维素成分较为复杂, 如图 1(b)所示, 其组织和纤维含量仅为 $60 \%$ 70\%, 此外还含有半 纤维素、木质素和果胶等 ${ }^{[5]}$, 因此 $\mathrm{BC}$ 呈现较好的化 学稳定性和热稳定性; 3$)$ 高持水能力 $(5000 \mathrm{wt} \%)$ 和 聚合度( 8000)。如图 1(c)所示, 高的持水能力是由 于纤维素独特的 3D 网络结构及表面含有大量羟基 所致; 4) 优异的机械性能。BC 拉伸强度和杨氏模量 分别可达 $20.8 \mathrm{GPa}$ 和 $357.3 \mathrm{MPa}$; 此外, $\mathrm{BC}$ 还呈现 较好的生物降解能力和生物相容性, 不仅绿色环保, 同时为与其他物质复合奠定了基础。目前所开发的 $\mathrm{BC}$ 功能产品在生物医药(人造血管、组织工程支架 和绷带)、食品、化妆品、造纸、光电设备、生物传 感、多功能配料等领域有着广泛的应用 ${ }^{[1]}$ 。近年来, 科研工作者进行了大量探索性研究, 致力于开拓 $\mathrm{BC}$ 在新材料、新能源和新技术等领域中的潜在应 用。

随着科技的不断发展，人们对新型能源材料的 需求日益迫切 ${ }^{[6-9]}$, 以超级电容器和以锂离子电池

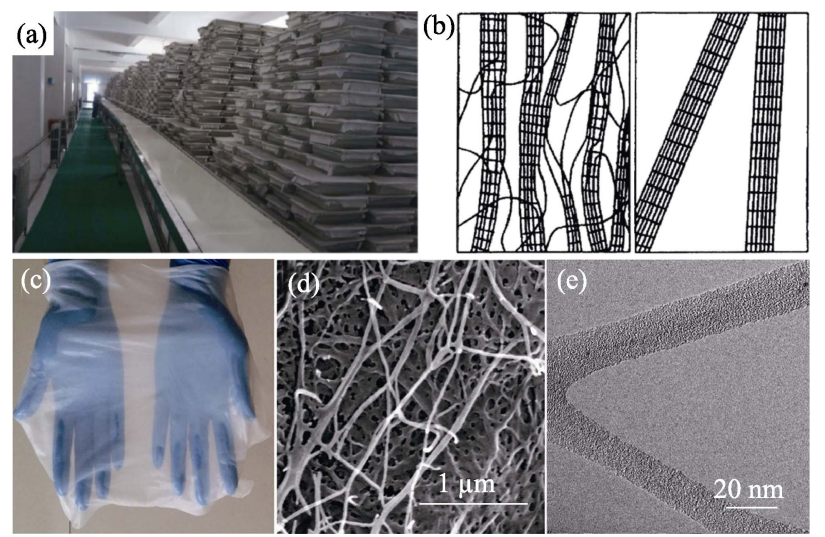

图 1 (a) $\mathrm{BC}$ 生产线照片 ${ }^{[3]}$; (b)植物纤维素(左)和 $\mathrm{BC}$ (右)模 型的比较 ${ }^{[5]}$; (c) BC 膜的实物、(d) SEM 及(e)TEM 照片 ${ }^{[4]}$

Fig. 1 (a) Photograph of the production line for $\mathrm{BC}^{[3]}$; (b) Schematic model of the plant cellulose fibrils (left) and the BC microfibers (right) ${ }^{[5]}$; (c) Photograph of BC slice; (d) SEM and (e)TEM images of $\mathrm{BC}^{[4]}$
为代表的二次电池是目前应用较为广泛的能源存储 设备。冊庸置疑，电极是能源存储设备中最为重要 的组成部件之一，因此，设计和构筑新型多功能的 高性能电极是当前面临的关键性问题。以 $\mathrm{BC}$ 为原 料制备的新型 $3 \mathrm{D}$ 碳纳米材料, 其通过引入杂原子 以实现 3D 碳纳米材料多功能化, 并且具有成本低 廉、可规模化生产的优点。更重要的是, $\mathrm{BC}$ 可直接 用于构建柔性电极的柔性基底。与传统基底相比, 柔性电极具有诸多优点：1) 制备策略具有通用性, 可与导电碳材料、金属氧化物和导电聚合物进行复 合，构筑不同结构的复合物柔性电极；2) 制备工艺 简单有效、成本低廉、环保并可规模化生产；3) 构 筑的柔性基底具有优异的机械性能, 保证电极在弯 曲和拉伸时的完整性；4）柔性基底具有充足的孔隙 和高持水 性, 有利于电活性物质和电解液的浸入, 增加与电活性物质的接触面, 并为电解液离子的传 输提供有效通道。

前期综述主要聚焦于不同纤维素、纤维素衍生 物和纤维素基复合物的制备及其在不同领域中的应 用, 但作为一种重要的纤维素, $\mathrm{BC}$ 还未被系统性地 研究。同时, 用 $\mathrm{BC}$ 制备 3D 碳纳米纤维(Carbon Nanofiber, CNF)活性材料、柔性基底和隔膜等应用 领域的重要性, $\mathrm{BC}$ 及复合物用于储能设备的优点等 相关话题亦未被关注。因此, 有必要全面概括关于 $\mathrm{BC}$ 及其复合材料的制备, 综述其在能源存储领域 的应用及强调该方向的重要性。本文总结了 $\mathrm{BC}$ 在 电极材料方面的应用，包括以下三个方面: 1) BC 作 为制备 $\mathrm{CNF}$ 的前驱体和生长复合物的模板，及其 作为电极材料在超级电容器方面的应用; 2) 以 $\mathrm{BC}$ 作为柔性衬底, 用于支撑碳材料、导电聚合物和金 属氧化物等活性物质, 并作为固态电解质在柔性 电容器中应用; 3) 在讨论目前 $\mathrm{BC}$ 基能源存储设备 存在问题的基础上, 对未来的研究方向进行展望, 包括在高性能二次电池, 比如锂离子电池 (LIB), 钠离子电池(NLB), 锌-空气电池等方面的潜在应 用价值。

\section{BC 在超级电容器中的应用}

超级电容器(Supercapacitors)又可称为电化学电 容器(Electrochemical capacitors), 是一种结合传统 电容器和锂离子电池二者优势的新型储能器件。由 于超级电容器具有超过商业化蓄电池的功率密度、 充放电效率高、循环寿命长、能量转换效率高、绿 色环保等诸多优点，已被广泛应用于航天、军事、 电动车和电子产品等领域。随着科技的快速发展, 
移动设备更多地偏向柔性、便携性、可穿戴性方向 开发。与此同时, 储能设备的关注焦点也集中于研 发轻薄、高功率的柔性能量存储装置。柔性超级电 容器凭借其优异的性能在各式可弯曲储能设备中具 有极大的开发潜力和发展前景 ${ }^{[10-11]}$ 。

按储能机理的不同, 可将超级电容器分为双电 层超级电容器(EDLCs) 和噟电容超级电容器两类。 其中, 前者是基于电极表面产生纯静电电荷吸附且 富集而产生的，而后者是通过氧化还原反应来存储 电荷的。基于此机理, 有效比表面积和孔结构对 EDLCs 的电容表现至关重要。因此, 具有较大的比 表面积、多孔结构、高导电性及快速充放电动力学 的碳材料, 如 CNT、活性炭 (AC)、碳纤维 $(\mathrm{CF})$ 和石 墨烯(RGO)等被广泛用作 EDLCs 电极材料。噟电容 超级电容器是以过渡金属氧化物和导电聚合物为电 活性物质, 通过快速可逆的法拉第氧化还原来实现 能量存储。与 EDLCs 相比, 噟电容超级电容器能贡 献更多的存储电荷和更高的能量密度, 但其氧化还 原反应过程中的体积膨胀和收缩会产生机械应力, 致使赝电容超级电容器具有较低的倍率性能和较差 的循环稳定性。

\subsection{BC 基碳材料电极}

如前文所述, 3D 碳纳米材料因诸多优点而引起 了广泛关注 ${ }^{[12-13]}$, 当前最为有效的制备方法包括化 学气相沉积法(CVD), 热解有机凝胶, 纳米碳材料 自组装等。然而, 这些方法存在装备复杂、生产成 本高、污染环境和产率低等缺点 ${ }^{[14]}$ 。因此, 开发一 种简便易行、环保和规模化方法制备 3D 碳纳米材 料迫在眉睫。此外, 除了活性材料的高性能, 多功能 性也逐渐成为研究热点。

$\mathrm{BC}$ 作为一种极其重要的纳米生物材料, 因众 多独特的优点而在储能领域得到广泛的发展。首先 将 $\mathrm{BC}$ 薄膜冷冻干燥以保持其三维网状结构, 然后 将其置于 $\mathrm{N}_{2}$ 中高温裂解生成 3D CNF 活性物质。测 试发现在 $2 \mathrm{~A} \cdot \mathrm{g}^{-1}$ 时, $3 \mathrm{D} \mathrm{CNF}$ 活性物质的质量比电 容可以达到 $108 \mathrm{~F} \cdot \mathrm{g}^{-1}$, 与 $\mathrm{CNF}\left(0.17 \mathrm{~F} \cdot \mathrm{g}^{-1}\right)^{[15]}$ 相比, 其质量比电容显著提高。为提高材料比电容, 在 $\mathrm{CNF}$ 材料中掺杂杂原子, 使得材料表面电活性位点 改变, 电子传输速率提高, 表面亲水性改善, 电容 特性显著增强。同时, 杂原子的孤对电子易与膜或 其他材料形成氢键作用力, 可进一步提高电极的循 环稳定性 ${ }^{[16]}$ 。研究发现, 材料中杂原子的含量与实 验过程的碳化温度相关, 即实验过程中的碳化温度 越高, 相应杂原子含量越低, 且所制备的碳材料的 石墨化程度越高、比表面积和介孔体积越大 ${ }^{[17]}$ 。这 证明材料中引入的杂原子对增强噟电容和双电层
电容有所帮助, 而且石墨化结构使得材料具有较 好的导电性和耐腐蚀性, 有助于提高电极的循环稳 定性。

Jiang 等 ${ }^{[18]}$ 采用的一步合成法, 将 $\mathrm{BC}$ 与柠檬酸 钠混合后再进行高温裂解，制备高导电 CNF 桥接多 孔碳纳米片(PCNs)。该研究中作为碳材料前驱体的 柠檬酸钠, 对反应热处理过程有化学活化作用。一 步法制备的 3D PCNs 具有高达 $1037 \mathrm{~m}^{2} \cdot \mathrm{g}^{-1}$ 的比表面 积, 电化学测试证明其质量比电容可以达到 $261 \mathrm{~F} \cdot \mathrm{g}^{-1}$, 并呈现优异的倍率性能和循环稳定性, 且在循环 $10^{4}$ 次后电容保持率仍有 $97.6 \%$ 。Long 等 ${ }^{[12]}$ 以聚苯 胺(PANI)为掺杂剂、 $\mathrm{KOH}$ 为活化剂得到相互交联、 多孔的 N-CNF，其比表面积高达 $1326 \mathrm{~m}^{2} \cdot \mathrm{g}^{-1}$ ，极大 地增强了电极的双电层和赝电容存储能力。Lai 等 ${ }^{[19]}$ 采用类似的方法制备了一种多孔结构的碳气凝胶, 其电化学性能表现较好, 而且可以作为多功能的吸 附剂。采用不同有机染料为掺杂剂, 可将毒性废物 转变为有价值的杂原子掺杂 $\mathrm{CNF}$ 气凝胶, 作为氧还 原反应(ORR) 和超级电容器的电催化剂和电极材 料 ${ }^{[20]}$ 。因此，该方法被证实是一种合理有效的策略， 并且可进一步扩展到开发其他掺杂电极材料, 如表 1 所示。

综上所述, 该材料具有成本低、原料来源广泛、 设备要求低、制造工艺简单且具有普适性等优点, 并适合于规模化生产，是一种有效用于构建具有高 功率密度和优异循环稳定性的高性能电极材料(表 1)。

\section{$1.2 \mathrm{BC}$ 基复合物电极}

噟电容器是以导电聚合物和过渡金属(氢)氧化 物为电活性材料, 通过快速可逆的法拉第反应传递 更高的比电容。整个过程中, 法拉第噟电容存在于 整个电极体系中, 而不只是发生在电极表面。同时, 活性材料表面的离子去向和电荷转移速度决定法拉 第噟电容的快速充放电性能, 因此电容器中的电荷 转移可在短时间内完成。一般情况下, 一个超级电 容器体系会同时存在两种储能机制, 即双电层电容 和噟电容, 系统以一种储能机制为主导方式, 另一 种作为系统辅助机制, 共同完成系统的充放电过 程。在电极面积相同的情况下, 噟电容的比电容约 高出双电层电容 1 2 个数量级, 即噟电容器具有更 高的能量密度。但与双电层吸附富集电荷的储能机 制而言, 噟电容器的法拉第氧化还原反应存储电荷 时间更长, 即与双电层电容器相比, 噟电容器提供 的功率密度较低 ${ }^{[21-22]}$ 。

此外, 由于体积膨胀和收缩所产生的机械应力, 致使噟电容器的倍率性能低且循环稳定性差; 而大 部分过渡金属(氢)氧化物的导电性差导致倍率性能 
表 1 BC 基碳材料超级电容器电极的电化学性能

Table 1 BC-based carbon material electrodes for supercapacitor

\begin{tabular}{|c|c|c|c|c|c|c|c|c|}
\hline Material & $\begin{array}{l}\text { Function } \\
\text { of BC }\end{array}$ & $\begin{array}{c}\text { Potential } \\
\text { window/V }\end{array}$ & $\begin{array}{l}\text { Capacitance/ } \\
\left(\mathrm{F} \cdot \mathrm{g}^{-1}\right)\end{array}$ & $\begin{array}{c}\text { Rate } \\
\text { capability }\end{array}$ & $\begin{array}{c}\text { Stability } \\
\text { (cycle number) }\end{array}$ & $\begin{array}{c}\text { Highest energy } \\
\text { density/ } \\
\left(\mathrm{Wh} \cdot \mathrm{kg}^{-1}\right)\end{array}$ & $\begin{array}{c}\text { Highest power } \\
\text { density/ } \\
\left(\mathrm{kW} \cdot \mathrm{kg}^{-1}\right)\end{array}$ & Ref. \\
\hline $\begin{array}{c}\mathrm{CO}_{2} \text { activated } \\
\mathrm{CNF}\end{array}$ & $\begin{array}{l}\text { Active } \\
\text { material }\end{array}$ & $\begin{array}{c}-0.2-0.2 \\
(v s . \mathrm{Ag} / \mathrm{AgCl})\end{array}$ & $\begin{array}{l}42\left(1 \mathrm{mV} \cdot \mathrm{s}^{-1}\right) \\
\left(659 \mathrm{mF} \cdot \mathrm{cm}^{-2}\right)\end{array}$ & $\begin{array}{c}70 \% \\
\left(10 \mathrm{mV} \cdot \mathrm{s}^{-1}\right)\end{array}$ & - & - & - & [14] \\
\hline $\mathrm{CNF}$ & $\begin{array}{l}\text { Active } \\
\text { material }\end{array}$ & $\begin{array}{c}-1-0 \\
\text { (vs. } \mathrm{Ag} / \mathrm{AgCl})\end{array}$ & $\begin{array}{c}108 \\
\left(2 \mathrm{~A} \cdot \mathrm{g}^{-1}\right)\end{array}$ & - & - & - & - & {$[15]$} \\
\hline $\mathrm{PCN} / \mathrm{CNF}$ & $\begin{array}{l}\text { Active } \\
\text { material }\end{array}$ & $\begin{array}{c}-1-0 \\
\text { (vs. } \mathrm{Hg} / \mathrm{HgO})\end{array}$ & $\begin{array}{c}261 \\
\left(2 \mathrm{mV} \cdot \mathrm{s}^{-1}\right)\end{array}$ & $\begin{array}{c}76.6 \\
\left(500 \mathrm{mV} \cdot \mathrm{s}^{-1}\right)\end{array}$ & $97.6 \%(10000)$ & - & - & {$[18]$} \\
\hline $\begin{array}{l}\mathrm{PCN} / \mathrm{CNF} / / \\
\mathrm{PCN} / \mathrm{CNF}\end{array}$ & $\begin{array}{l}\text { Active } \\
\text { material }\end{array}$ & $0-1.8$ & - & - & $94.8 \%(10000)$ & 20.4 & 17.8 & {$[18]$} \\
\hline $\begin{array}{l}\mathrm{N}, \mathrm{P}-\mathrm{CNF} / / \\
\mathrm{N}, \mathrm{P}-\mathrm{CNF}\end{array}$ & $\begin{array}{l}\text { Active } \\
\text { material }\end{array}$ & $0-1$ & $\begin{array}{c}204.9 \\
\left(1 \mathrm{~A} \cdot \mathrm{g}^{-1}\right)\end{array}$ & - & $100 \%(4000)$ & 7.76 & 26.1 & {$[2]$} \\
\hline $\mathrm{N}-\mathrm{S}-\mathrm{CNF}-700$ & $\begin{array}{l}\text { Active } \\
\text { material }\end{array}$ & $\begin{array}{c}0-1 \\
\text { (vs. } \mathrm{Ag} / \mathrm{AgCl})\end{array}$ & $\begin{array}{c}171.2 \\
\left(0.5 \mathrm{~A} \cdot \mathrm{g}^{-1}\right)\end{array}$ & $105.2\left(10 \mathrm{~A} \cdot \mathrm{g}^{-1}\right)$ & $>90 \%(1000)$ & - & - & [20] \\
\hline $\begin{array}{l}\mathrm{KOH} \text { activated } \\
\mathrm{N}-\mathrm{CNF}\end{array}$ & $\begin{array}{l}\text { Active } \\
\text { material }\end{array}$ & $\begin{array}{c}0.9-0.1 \\
(v s . \mathrm{SHE})\end{array}$ & $296\left(2 \mathrm{mV} \cdot \mathrm{s}^{-1}\right)$ & $\begin{array}{c}75 \% \\
\left(500 \mathrm{mV} \cdot \mathrm{s}^{-1}\right)\end{array}$ & $99 \%(10000)$ & - & - & {$[12]$} \\
\hline $\mathrm{N}-\mathrm{CNF}$ & $\begin{array}{l}\text { Active } \\
\text { material }\end{array}$ & $\begin{array}{c}-1-0 \\
\text { (vs. } \mathrm{Ag} / \mathrm{AgCl})\end{array}$ & $120\left(1 \mathrm{~A} \cdot \mathrm{g}^{-1}\right)$ & - & $98.2 \%(5000)$ & - & - & [13] \\
\hline $\mathrm{N}, \mathrm{P}-\mathrm{CNWs}$ & $\begin{array}{l}\text { Active } \\
\text { material }\end{array}$ & $\begin{array}{c}-1-0 \\
\text { (vs. } \mathrm{Hg} / \mathrm{HgO})\end{array}$ & $258\left(1 \mathrm{~A} \cdot \mathrm{g}^{-1}\right)$ & $208\left(10 \mathrm{~A} \cdot \mathrm{g}^{-1}\right)$ & $98 \%(30000)$ & - & - & [26] \\
\hline $\begin{array}{c}\mathrm{N}, \mathrm{P}-\mathrm{CNWs} / / \\
\mathrm{N}, \mathrm{P}-\mathrm{CNWs}\end{array}$ & $\begin{array}{l}\text { Active } \\
\text { material }\end{array}$ & $0-1$ & $74\left(0.5 \mathrm{~A} \cdot \mathrm{g}^{-1}\right)$ & - & $87 \%$ (6000) & 5.4 & 0.2 & [26] \\
\hline CNF aerogels & $\begin{array}{l}\text { Active } \\
\text { material }\end{array}$ & $\begin{array}{c}-1-0 \\
\text { (vs. } \mathrm{Ag} / \mathrm{AgCl})\end{array}$ & $\begin{array}{c}194.7 \\
\left(0.5 \mathrm{~A} \cdot \mathrm{g}^{-1}\right)\end{array}$ & $108.7\left(10 \mathrm{~A} \cdot \mathrm{g}^{-1}\right)$ & $94 \%(5000)$ & - & - & [19] \\
\hline
\end{tabular}
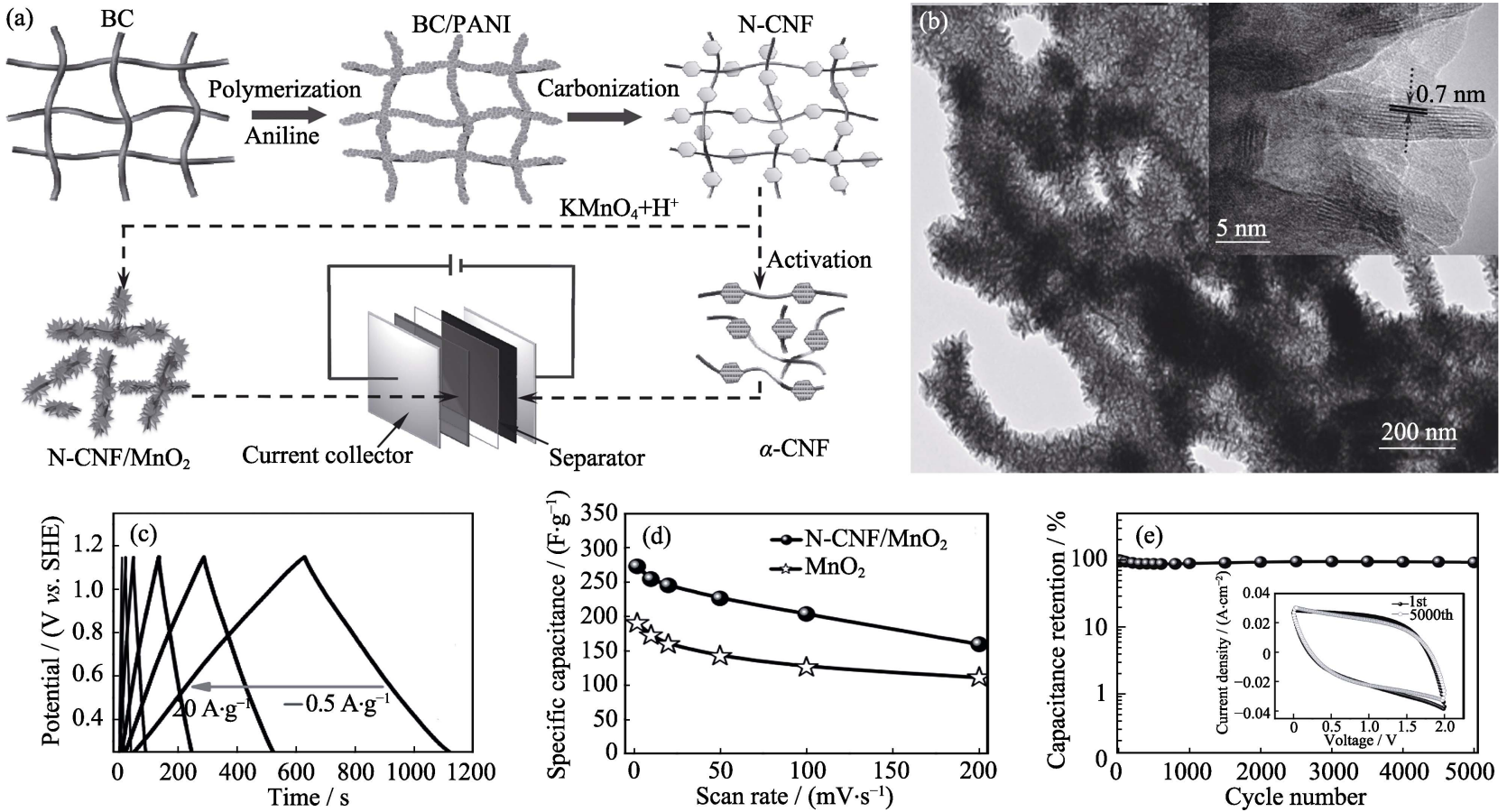

图 2 (a)非对称型超级电容器的原理图, (b)N-CNF/ $\mathrm{MnO}_{2}$ 的 $\mathrm{TEM}$ 照片, (c)N-CNF/ $\mathrm{MnO}_{2}$ 电极的 GCD 曲线, (d) 质量比电容和(e)循环稳定性测试 ${ }^{[12]}$

Fig. 2 (a) Schematic diagram for asymmetric supercapacitor device; (b) TEM images, (c) GCD curves, (d) specific capacitance and (e) cycle performance of $\mathrm{N}-\mathrm{CNF} / \mathrm{MnO}_{2}{ }^{[12]}$

较低，因此当下研究的热点在于将过渡金属(氢)氧 化物与相应高稳定性、高电导率的碳质材料复合,
改善单一材料的缺陷, 从而制备出具有高性能表现 的复合物基电极。 
前面介绍 $\mathrm{CNF}$ 是一种较为理想的碳基电极材 料, 通过与高噟电容材料结合实现高比电容和能量 密度的复合电极材料。 $\mathrm{Liu}$ 等 ${ }^{[23]}$ 选择 N-CNF 作为主 体骨架，超薄 Ni-Co 双氢氧化物纳米层在其表面沉 积，进而得到 N-CBC@LDH。经测试检验，实验制得 的电极表现出较好的循环稳定性(在 $5 \times 10^{3}$ 次循环后 电容仍可保持 $74.4 \%$ ) 以及较高的比电容 $\left(1949.5 \mathrm{~F} \cdot \mathrm{g}^{-1}\right)$ 。 $\mathrm{Yu}$ 等 ${ }^{[15]}$ 采用高温裂解和水热反应制备另一种复合 物 $\mathrm{Ni}_{3} \mathrm{~S}_{2} / \mathrm{CNF}$ ，经电化学测试后发现，实验所制备的 $\mathrm{Ni}_{3} \mathrm{~S}_{2} / \mathrm{CNF}$ 电极的比电容可达到 $883 \mathrm{~F} \cdot \mathrm{g}^{-1}$, 是 $\mathrm{CNF}$ $\left(108 \mathrm{~F}^{\circ} \mathrm{g}^{-1}\right)$ 的 7 倍。 $\mathrm{MnO}_{2}$ 具有价格低廉、理论噟电 容高和环境友好等优点, Long 等 ${ }^{[12]}$ 以 PANI 为掺杂 剂, 将 $\mathrm{MnO}_{2}$ 晶体生长在 $\mathrm{N}-\mathrm{CNF}$ 表面, 得到了 $\mathrm{N}-\mathrm{CNF} /$ $\mathrm{MnO}_{2}$ 正极材料(图 2(a)), TEM 测试发现 $5 \mathrm{~nm}$ 厚和层 间距为 $0.7 \mathrm{~nm}$ 的 $\mathrm{MnO}_{2}$ 纳米层均匀地分散在 $\mathrm{CNF}$
表面(图 2(b))。如图 2(c d) 所示，该正极在 $2 \mathrm{mV} \cdot \mathrm{s}^{-1}$ 时比电容可达到 $273 \mathrm{~F} \cdot \mathrm{g}^{-1}$, 在 $100 \mathrm{mV} \cdot \mathrm{s}^{-1}$ 时电容值 仍然保持在 $75 \%$ 。非对称型电容器采用 $\mathrm{N}-\mathrm{CNF}$ 为 负极材料, 其能量密度高达 $63 \mathrm{Wh} \cdot \mathrm{kg}^{-1}$, 并且展现 出优异的循环稳定性(图 2(e))。这主要归因于电解液 离子快速可逆的嵌入/脱出和 $\mathrm{MnO}_{2}$ 与导电碳网络之 间快速的电荷转移速度。Chen 等 ${ }^{[24]}$ 制备的非对称型 电容器 $\mathrm{CNF} @ \mathrm{MnO}_{2} / / \mathrm{N}-\mathrm{CNF}$ 是以尿素为掺杂剂, 其 所能达到的最大能量密度为 $284.63 \mathrm{~kW} \cdot \mathrm{kg}^{-1}$, 且在 循环 $2 \times 10^{3}$ 次后，其电容值仍保持在 $95.4 \%$ 。

Chen 等 ${ }^{[25]}$ 采用此方法设计了一种全固态超级 电容器, 该电容器展现出 $390.53 \mathrm{~kW} \cdot \mathrm{kg}^{-1}$ 的能量密 度和 $5 \times 10^{3}$ 次后电容值保持 $95.9 \%$ 的循环稳定性。 Chen 等 ${ }^{[2]}$ 利用不同掺杂剂, 制备 $P 、 N / P 、 B / P$ 等不 同杂原子掺杂的 $3 \mathrm{D}$ 碳纳米材料(图 3(a))。元素分布

(a)
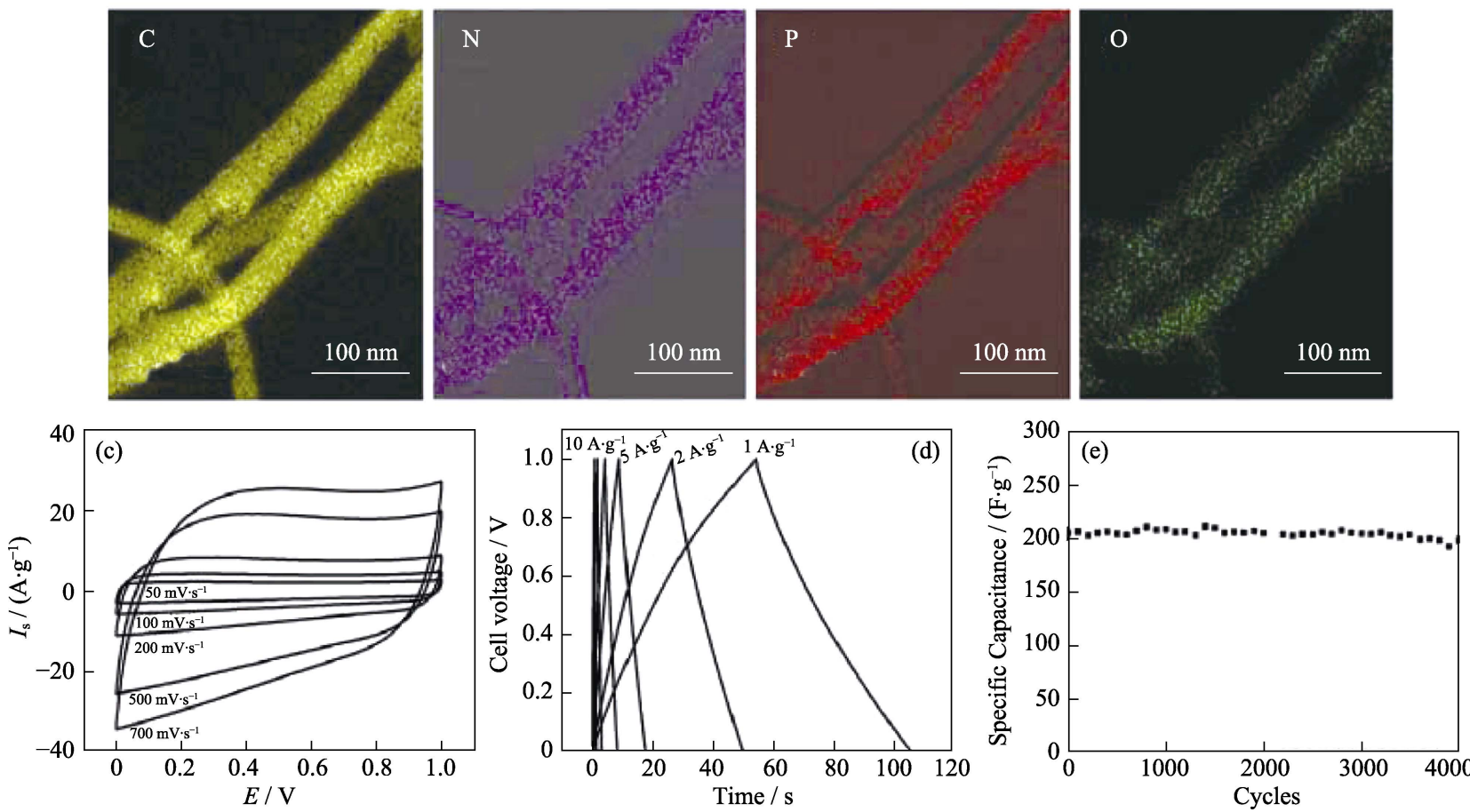

图 3 (a)杂原子掺杂 CNF 的制备流程图, (b)映射图像, (c) CV 曲线, (d) GCD 曲线和(e)循环稳定性测试 ${ }^{[2]}$

Fig. 3 (a) Fabrication process of heteroatom-doped CNF; (b) Elemental mapping images of C, N, P, and O for N, P-CNF; (c) CV curves, (d) GCD curves and (e) cycling stability test of N,P-CNF supercapacitor ${ }^{[2]}$ 
图可以清晰地观察到杂原子有效地掺杂并高度分散 在 3D 碳纳米材料中 (图 3(b)), 对称型电容器 $\mathrm{N}, \mathrm{P}-\mathrm{CNF} / \mathrm{N}, \mathrm{P}-\mathrm{CNF}$ 呈现较好的可逆性(图 3(c)) 和倍 率性能(图 3(d)), 高的能量密度(7.76 Wh $\mathrm{kg}^{-1}$ ) 和功 率密度 $\left(186.03 \mathrm{~kW} \cdot \mathrm{kg}^{-1}\right)$, 循环 $4 \times 10^{3}$ 次后比电容并 没有衰减(图 3(e))。这些优异性能归因于双掺杂和多 孔网络结构, 使材料中电子传输速度加快, 离子扩 散途径缩短, 从而提高电极材料的面积比电容。

$\mathrm{Hu}$ 等 ${ }^{[26]}$ 以 $\mathrm{NH}_{4} \mathrm{H}_{2} \mathrm{PO}_{4}$ 为掺杂剂, 将 $\mathrm{BC}$ 置于 $\mathrm{NH}_{3}$ 氛围中在 $800{ }^{\circ} \mathrm{C}$ 裂解, 制备双杂原子掺杂碳纳 米线 $(\mathrm{CNWs})$ 。通常, $\mathrm{N}$ 掺杂碳材料结构中包含四种 不同键合类型，即吡咯型 $\mathrm{N}(\mathrm{N}-5)$ 、吡啶型 $\mathrm{N}(\mathrm{N}-6)$ 、 石墨型 $\mathrm{N}(\mathrm{N}-\mathrm{Q})$ 和氧化型 $\mathrm{N}(\mathrm{N}-$ oxide)。其中, $\mathrm{N}-5$ 和 $\mathrm{N}-6$ 可以提供额外的赝电容, N-Q 可以增加材料 的导电性, 而 $\mathrm{N}$-oxide 可以提高电极材料的亲水 性 ${ }^{[27-29]}$ 。为了控制杂原子掺杂量, Liu 等 ${ }^{[16]}$ 采用双掺 杂剂的方法, 配比不同含量的 $\mathrm{NH}_{4} \mathrm{H}_{2} \mathrm{PO}_{4}$ 和 $\mathrm{CO}\left(\mathrm{NH}_{2}\right)_{2}$ 制备 N,P-CNF。

气凝胶是一类具有低密度、低导热性、良好耐 腐蚀性、高比表面积和高导电性的三维纳米多孔材
料，在催化剂载体、油/水分离、储氢、传感等领域 有着广泛的应用 ${ }^{[30-33]}$ 。 $\mathrm{Xu}$ 等 ${ }^{[34]}$ 以 $\mathrm{BC}$ 为前驱体合 成了介孔和高石墨化的具有核一壳结构的碳气凝胶, 电化学测试表明该电极面积比电容为 $78.7 \mu \mathrm{F} \cdot \mathrm{cm}^{-2}$, 对于以后的研究具有指导意义。

导电聚合物具有形貌可控、导电性好及赝电容 高等优点，可以通过原位化学反应或电化学聚合制 备而成 ${ }^{[35-36]}$ 。但是较差的循环稳定性严重限制了其 进一步发展, 而碳材料则具有较好的电化学稳定性, 将两者复合有望应用于高性能电容器电极。Muller 等 ${ }^{[37}$ 通过原位聚合将聚吡咯(PPY)均匀地包覆在 $\mathrm{BC}$ 纳米纤维表面形成具有核壳结构的 $\mathrm{PPY} / \mathrm{BC}$ 复 合物。复合物结构的改变主要依靠参数的相应调整, 导电率达到 $77 \mathrm{~S} \cdot \mathrm{cm}^{-1}$, 比此前的文献报道高出 3 个 数量级, $\mathrm{PPY} / \mathrm{BC}$ 的比电容为 $316 \mathrm{~F} \cdot \mathrm{g}^{-1}$ 。为了进一步 改善导电性和电容性能, Liu 等 ${ }^{[38]}$ 引入 GO 构筑 $3 \mathrm{D}$ 互穿网络 $\mathrm{PPY} / \mathrm{BC} / \mathrm{GO}$ 复合材料, 该结构为电解液 传输提供足够的空隙, 并增加可接触界面。如图 4 所 示, $\mathrm{PPY}$ 均匀地包覆在整个 $\mathrm{BC} / \mathrm{GO}$ 复合物中(图 4(f))。 三元 $\mathrm{PPY} / \mathrm{BC} / \mathrm{GO}$ 复合材料不仅构成了导电 $3 \mathrm{D}$ 网络,
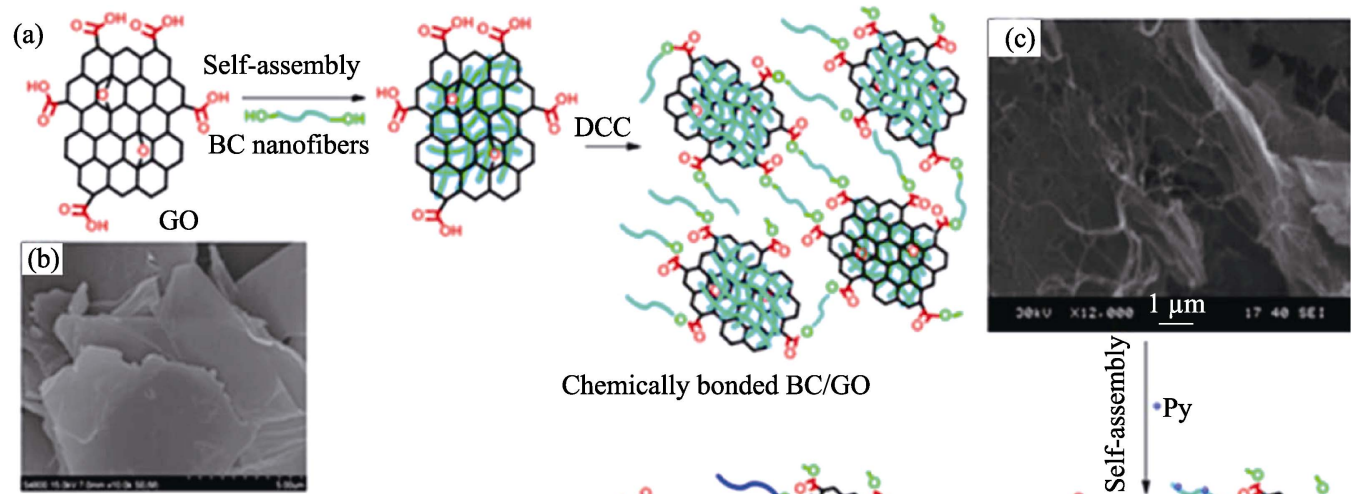

Chemically bonded BC/GO
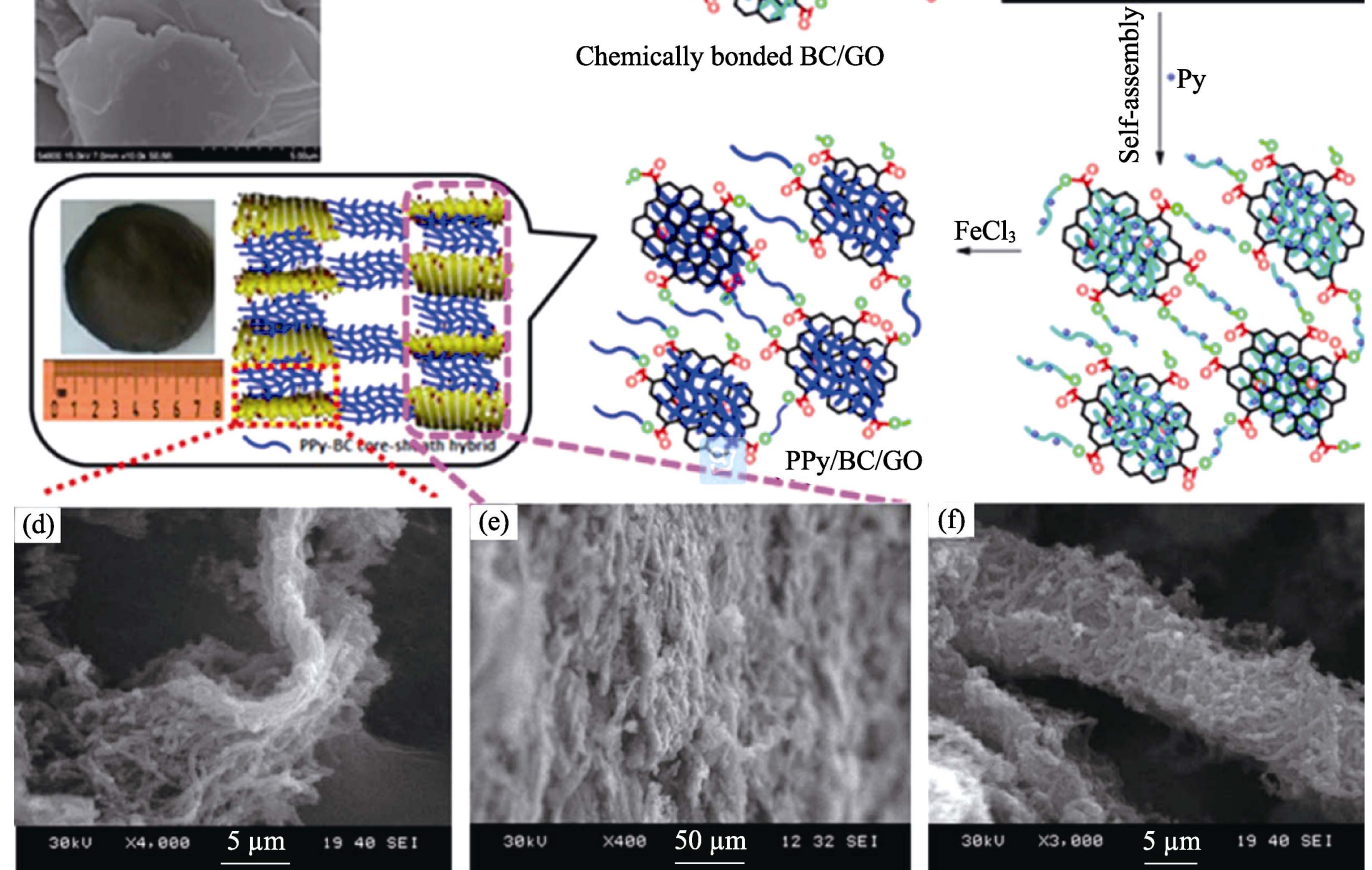

图 4 (a)PPY/BC/GO 复合物的制备流程图, (b f)不同物质的 SEM 照片 ${ }^{[38]}$

Fig. 4 (a) Synthesis scheme of PPY/BC/GO composites; SEM images of (b) pristine GO, (c) cross-linked BC/GO, (d) a single layer and (e) multilayers of PPY/BC/GO hybrid, and (f) PPY/BC core-sheath hybrid ${ }^{[38]}$ 
同时抑制了 GO 层的堆叠和 PPY 的团聚(图 4(d e ))。 该复合物材料电导率为 $1320 \mathrm{~S} \cdot \mathrm{m}^{-1}$, 非对称超级电 容器比电容达到 $556 \mathrm{~F} \cdot \mathrm{g}^{-1}\left(278 \mathrm{~F} \cdot \mathrm{cm}^{-3}\right)$ 。因此, 这种 低成本、环保的生物材料 CNF 基复合电极对于构建 高性能超级电容器具有重要的启发意义(表 2)。

\section{BC 在柔性超级电容器中的应用}

随着柔性、便携、可穿戴电子设备的日益兴起, 高性能柔性电极材料的设计与构筑引起了极大关 注。与传统电极不同, 柔性电极必须具备高柔性 ${ }^{[39-40]}$ 和稳定性，衡量柔性电极的重要标准主要包括其面 积/质量/体积比电容、负载量、机械性能、循环性 能等综合因素。面积/体积比电容相对于质量比电容 更适合作为柔性电极电化学性能表征的参数, 目的 是在有限的面积下提供更高的能量密度。面积/体积 比电容的提升可通过提高活性物质的质量比电容及 单位面积/体积负载量来获得。纸基材料是最具潜力 的柔性基底, 不仅具有成本低、质轻、高柔性及环 保等特点, 而且可以与碳基材料或导电聚合物等导 电材料形成复合材料。基于此, 本课题组以 $\mathrm{BC}$ 为 基底，制备了几种不同种类的高性能的柔性电极, 并验证了该方法的普适性。

\subsection{BC 基 EDLCs 柔性电极}

碳材料, 如 CNT、CNF 和 RGO 已被用于开发
柔性超级电容器。CNT 直接过滤涂覆在高柔性纸基 祄底上，不仅形成连续导通网络，同时赋予整个电 极高柔性。Kang 等 ${ }^{[41]}$ 采用真空过滤的方法将 CNT 墨汁沉积在厚度约为 $10 \mu \mathrm{m}$ 的 $\mathrm{BC}$ 纸上得到 $\mathrm{BC} / \mathrm{CNT}$ 柔性电极。如图 5(a)所示, $\mathrm{BC} / \mathrm{CNT}$ 膜具有 优异的机械稳定性, 即使弯折上百次也不会出现分 层(图 5(b))。SEM 截面照片(图 5(c)) 可以看出 CNT 的沉积厚度约为 $5 \mu \mathrm{m}$, 并且二者之间紧密连接。 $\mathrm{BC} /$ CNT 柔性电极具有良好的电容和高库伦效率(图 5(d)), 多次弯折后其比电容并未有明显变化(图 5(e)), 在 实际储能应用领域有很大的应用潜力(图 5(f))。

RGO 具有比表面积高 $\left(2630 \mathrm{~m}^{2} \cdot \mathrm{g}^{-1}\right)$ 、导电性好 $\left(104 \mathrm{~S} \cdot \mathrm{cm}^{-1}\right)$ 、电化学稳定性好及可自身成膜等优 点 ${ }^{[42]}$ 。Xiong 等 ${ }^{[43]}$ 将 $\mathrm{GO}$ 水凝胶还原为高导电 $\mathrm{RGO}$ 柔性膜, 构筑的柔性电容器在 $1 \mathrm{~mA} \cdot \mathrm{cm}^{-2}$ 时的面积 比电容为 $71 \mathrm{mF} \cdot \mathrm{cm}^{-2}$, 在 $100 \mathrm{~mA} \cdot \mathrm{cm}^{-2}$ 时电容保持 率为 $79.0 \%$, 让人惊喜的是弯折 $180^{\circ}$ 几乎没有电容 损失。然而近期研究发现自支撑 RGO 存在团聚及 机械强度低等问题，Liu 等 ${ }^{[44]}$ 采用一步酯化法合成 具有 $3 \mathrm{D}$ 网络的 $\mathrm{BC} / \mathrm{GO}$ 柔性复合物电极。该电极拉 伸强度可达到 $18.48 \mathrm{MPa}$ ，明显高于 $\mathrm{RGO}$ 纸((1.91土 0.08) MPa)。此外，该膜的断裂伸长率和杨氏模量分 别为 $24 \%$ 和 $77 \mathrm{MPa}$ 。因此, BC 是制备柔性 CNT 和 $\mathrm{RGO}$ 电极的理想祄底, 并有望用于其它碳基柔性电 极的制备。

表 2 BC 基复合材料超级电容器电极的电化学性能

Table 2 BC-based composites electrodes for supercapacitor

\begin{tabular}{|c|c|c|c|c|c|c|c|c|}
\hline Material & $\begin{array}{l}\text { Function } \\
\text { of BC }\end{array}$ & $\begin{array}{l}\text { Potential } \\
\text { window/V }\end{array}$ & $\begin{array}{c}\text { Capacitance/ } \\
\left(\mathrm{F} \cdot \mathrm{g}^{-1}\right)\end{array}$ & Rate capability & $\begin{array}{l}\text { Stability } \\
\text { (cycle } \\
\text { number) }\end{array}$ & $\begin{array}{c}\text { Highest } \\
\text { energy } \\
\text { density/ } \\
\left(\mathrm{Wh} \cdot \mathrm{kg}^{-1}\right)\end{array}$ & $\begin{array}{c}\text { Highest } \\
\text { power } \\
\text { density/ } \\
\left(\mathrm{kW} \cdot \mathrm{kg}^{-1}\right)\end{array}$ & Ref. \\
\hline 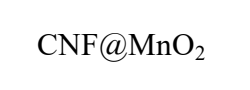 & $\begin{array}{l}\text { Active } \\
\text { material }\end{array}$ & $\begin{array}{c}0-1 \\
(v s . \mathrm{Ag} / \mathrm{AgCl})\end{array}$ & $\begin{array}{c}254.64 \\
\left(1 \mathrm{~A} \cdot \mathrm{g}^{-1}\right)\end{array}$ & $\begin{array}{c}77.53 \% \\
\left(10 \mathrm{~A} \cdot \mathrm{g}^{-1}\right)\end{array}$ & - & - & - & {$[24]$} \\
\hline $\begin{array}{c}\mathrm{CNF} @ \mathrm{MnO}_{2} / / \\
\mathrm{N}-\mathrm{CNF}\end{array}$ & $\begin{array}{l}\text { Active } \\
\text { material }\end{array}$ & $0-2$ & - & - & $95.4 \%(2000)$ & 32.91 & 284.63 & {$[24]$} \\
\hline $\mathrm{Ni}_{3} \mathrm{~S}_{2} / \mathrm{CNF}$ & $\begin{array}{l}\text { Active } \\
\text { material }\end{array}$ & $\begin{array}{c}0-0.6 \\
(v s . \mathrm{Ag} / \mathrm{AgCl})\end{array}$ & $\begin{array}{c}957 \\
\left(1 \mathrm{~A} \cdot \mathrm{g}^{-1}\right)\end{array}$ & $703\left(8 \mathrm{~A} \cdot \mathrm{g}^{-1}\right)$ & $16.5 \%(1000)$ & - & - & {$[15]$} \\
\hline $\mathrm{Ni}_{3} \mathrm{~S}_{2} / \mathrm{CNF} / / \mathrm{CNF}$ & $\begin{array}{l}\text { Active } \\
\text { material }\end{array}$ & $0-1.7$ & $\begin{array}{c}56.6 \\
\left(1 \mathrm{~A} \cdot \mathrm{g}^{-1}\right)\end{array}$ & $35.4\left(10 \mathrm{~A} \cdot \mathrm{g}^{-1}\right)$ & $97 \%(2500)$ & 25.8 & 0.425 & {$[15]$} \\
\hline $\mathrm{CNF} / \mathrm{MnO}_{2}$ & $\begin{array}{l}\text { Active } \\
\text { material }\end{array}$ & $\begin{array}{l}0.15-1.15 \\
\text { (vs. SCE) }\end{array}$ & $\begin{array}{c}273 \\
\left(2 \mathrm{mV} \cdot \mathrm{s}^{-1}\right)\end{array}$ & $\begin{array}{c}75 \% \\
\left(100 \mathrm{mV} \cdot \mathrm{s}^{-1}\right)\end{array}$ & - & - & - & {$[12]$} \\
\hline $\mathrm{CNF} / / \mathrm{CNF} / \mathrm{MnO}_{2}$ & $\begin{array}{l}\text { Active } \\
\text { material }\end{array}$ & $0-2$ & $\begin{array}{c}113 \\
\left(20 \mathrm{mV} \cdot \mathrm{s}^{-1}\right)\end{array}$ & $\begin{array}{c}53 \% \\
\left(10 \sim 200 \mathrm{mV} \cdot \mathrm{s}^{-1}\right)\end{array}$ & $92 \%(5000)$ & 63 & 8 & {$[12]$} \\
\hline N-CNF@LDH & $\begin{array}{l}\text { Active } \\
\text { material }\end{array}$ & $\begin{array}{c}0-0.5 \\
(\mathrm{Ag} / \mathrm{AgCl})\end{array}$ & $\begin{array}{l}1949.5 \\
\left(1 \mathrm{~A} \cdot \mathrm{g}^{-1}\right)\end{array}$ & $54.7\left(10 \mathrm{~A} \cdot \mathrm{g}^{-1}\right)$ & $74.4 \%(5000)$ & - & - & {$[23]$} \\
\hline $\begin{array}{c}\mathrm{N}-\mathrm{CNF} @ \mathrm{LDH} / / \\
\mathrm{N}-\mathrm{CNF}\end{array}$ & $\begin{array}{l}\text { Active } \\
\text { material }\end{array}$ & $0-1.6$ & $101.9\left(1 \mathrm{~A} \cdot \mathrm{g}^{-1}\right)$ & $63.8\left(10 \mathrm{~A} \cdot \mathrm{g}^{-1}\right)$ & $89.3 \%(2500)$ & 36.3 & 8 & [23] \\
\hline
\end{tabular}



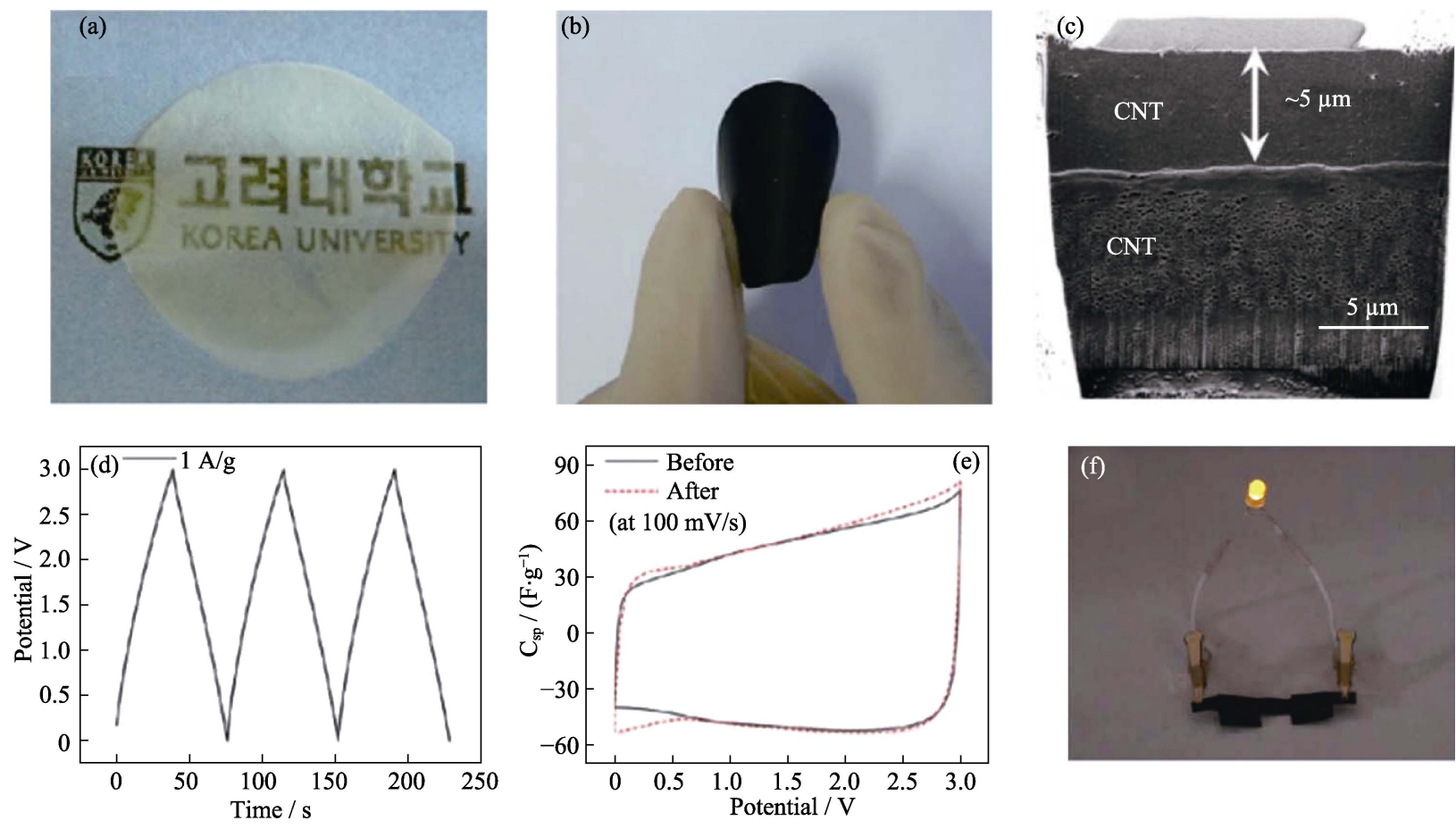

图 5 (a)BC 纸和(b)CNT/BC 纸的照片; (c)CNT/BC 纸的 SEM 截面照片; 柔性超级电容器的

(d)GCD 曲线和(e)CV 曲线; (f)柔性超级电容器照片 ${ }^{[41]}$

Fig. 5 Photographs of (a) BC paper and (b) flexible CNT/BC paper; (c) Cross-sectional image of CNT/BC paper; (d) GCD curve and (e) CV curves for CNT/BC/ion gel flexible supercapacitors; (f) Photograph of a LED turned on by the flexible supercapacitors ${ }^{[41]}$

表 3 BC 基柔性超级电容器电极的电化学性能

Table 3 BC-based electrodes for flexible EDLCs

\begin{tabular}{|c|c|c|c|c|c|c|c|c|c|}
\hline Material & Function of BC & $\begin{array}{l}\text { Potential } \\
\text { window/V }\end{array}$ & $\begin{array}{l}\text { Capacitance/ } \\
\left(\mathrm{mF} \cdot \mathrm{cm}^{-2}\right)\end{array}$ & $\begin{array}{c}\text { Capacitance/ } \\
\left(\mathrm{F} \cdot \mathrm{g}^{-1}\right)\end{array}$ & $\begin{array}{c}\text { Rate } \\
\text { capability }\end{array}$ & $\begin{array}{l}\text { Stability } \\
\text { (cycle } \\
\text { number) }\end{array}$ & $\begin{array}{l}\text { Highest } \\
\text { energy } \\
\text { density }\end{array}$ & $\begin{array}{l}\text { Highest } \\
\text { power } \\
\text { density }\end{array}$ & Ref. \\
\hline $\mathrm{N}-\mathrm{CNF} / \mathrm{RGO} / \mathrm{BC}$ & $\begin{array}{l}\text { Active material } \\
\& \text { substrate }\end{array}$ & $\begin{array}{c}-0.8-0.2 \\
(v s . \mathrm{Hg} / \mathrm{HgO})\end{array}$ & $\begin{array}{c}2106 \\
\left(1 \mathrm{mV} \cdot \mathrm{s}^{-1}\right)\end{array}$ & 263 & $\begin{array}{c}76 \% \\
\left(50 \mathrm{mV} \cdot \mathrm{s}^{-1}\right)\end{array}$ & $\begin{array}{c}100 \% \\
\left(2 \times 10^{4}\right)\end{array}$ & - & - & {$[45]$} \\
\hline $\begin{array}{l}\mathrm{N}-\mathrm{CNF} / \mathrm{RGO} / \mathrm{BC} / / \\
\mathrm{N}-\mathrm{CNF} / \mathrm{RGO} / \mathrm{BC}\end{array}$ & $\begin{array}{l}\text { Active material } \\
\& \text { substrate }\end{array}$ & $0-1$ & $\begin{array}{c}810 \\
\left(2 \mathrm{mV} \cdot \mathrm{s}^{-1}\right)\end{array}$ & - & $\begin{array}{c}755 \\
\left(50 \mathrm{mV} \cdot \mathrm{s}^{-1}\right)\end{array}$ & $\begin{array}{c}99.6 \% \\
\left(10^{4}\right)\end{array}$ & $\begin{array}{c}0.11 \\
\mathrm{mWh} \cdot \mathrm{cm}^{-2}\end{array}$ & $\begin{array}{c}27 \\
\mathrm{~mW} \cdot \mathrm{cm}^{-2}\end{array}$ & [46] \\
\hline $\mathrm{N}, \mathrm{P}-\mathrm{CNF} / \mathrm{RGO} / \mathrm{BC}$ & $\begin{array}{c}\text { Active material } \\
\& \text { substrate }\end{array}$ & $\begin{array}{c}-0.8-0.2 \\
(\text { vs. } \mathrm{Hg} / \mathrm{HgO})\end{array}$ & $\begin{array}{c}1900 \\
\left(2 \mathrm{mV} \cdot \mathrm{s}^{-1}\right)\end{array}$ & 244.8 & $\begin{array}{c}1554 \\
\left(50 \mathrm{mV} \cdot \mathrm{s}^{-1}\right)\end{array}$ & $\begin{array}{c}100 \% \\
\left(2 \times 10^{4}\right)\end{array}$ & - & - & [16] \\
\hline $\begin{array}{c}\mathrm{N}, \mathrm{P}-\mathrm{CNF} / \mathrm{RGO} / \\
\mathrm{BC} / / \mathrm{N}, \mathrm{P}-\mathrm{CNF} / \\
\mathrm{RGO} / \mathrm{BC}\end{array}$ & $\begin{array}{l}\text { Active material } \\
\& \text { substrate }\end{array}$ & $0-1$ & $\begin{array}{c}690 \\
\left(2 \mathrm{mV} \cdot \mathrm{s}^{-1}\right)\end{array}$ & - & $\begin{array}{c}620 \\
\left(40 \mathrm{mV} \cdot \mathrm{s}^{-1}\right)\end{array}$ & $\begin{array}{l}99.6 \% \\
\left(1 \times 10^{4}\right)\end{array}$ & $\begin{array}{c}0.096 \\
\mathrm{mWh} \cdot \mathrm{cm}^{-2}\end{array}$ & $\begin{array}{c}19.98 \\
\mathrm{~mW} \cdot \mathrm{cm}^{-2}\end{array}$ & [16] \\
\hline BC/GO electrode & Scaffold & $\begin{array}{l}-0.2-0.8 \\
(v s . \text { SCE })\end{array}$ & - & $\begin{array}{c}160 \\
\left(0.4{\left.\mathrm{~A} \cdot \mathrm{g}^{-1}\right)}\right.\end{array}$ & $\begin{array}{c}68 \\
\left(2 \mathrm{~A} \cdot \mathrm{g}^{-1}\right)\end{array}$ & $\begin{array}{l}90.3 \% \\
\left(2 \times 10^{3}\right)\end{array}$ & - & - & [44] \\
\hline $\begin{array}{l}\mathrm{BC} / \mathrm{CNT} / \text { ion gel } \\
\text { supercapacitors }\end{array}$ & Substrate & $0-3$ & $\begin{array}{c}18.8 \\
\left(100 \mathrm{mV} \cdot \mathrm{s}^{-1}\right)\end{array}$ & 46.9 & $\begin{array}{c}42.0 \\
\left(500 \mathrm{mV} \cdot \mathrm{s}^{-1}\right)\end{array}$ & $\begin{array}{l}99.5 \% \\
\left(5 \times 10^{4}\right)\end{array}$ & $\begin{array}{c}15.5 \\
\mathrm{Wh} \cdot \mathrm{kg}^{-1}\end{array}$ & $\begin{array}{c}1.5 \\
\mathrm{~kW} \cdot \mathrm{kg}^{-1}\end{array}$ & [41] \\
\hline $\begin{array}{c}\text { a-CNF//BC gel// } \\
\text { a-CNF superca- } \\
\text { pacitors }\end{array}$ & $\begin{array}{c}\text { Active material } \\
\& \text { electrolyte \& } \\
\text { separator }\end{array}$ & $0-1$ & $\begin{array}{c}289 \\
\left(0.1 \mathrm{~mA} \cdot \mathrm{cm}^{-2}\right)\end{array}$ & - & $\begin{array}{c}70 \% \\
\left(10 \mathrm{~mA} \cdot \mathrm{cm}^{-2}\right)\end{array}$ & $\begin{array}{l}66.7 \% \\
(100)\end{array}$ & - & - & {$[60]$} \\
\hline
\end{tabular}

$\mathrm{Liu}$ 等 ${ }^{[16]}$ 制备的双原子掺杂的柔性电极 $\mathrm{N}, \mathrm{P}-\mathrm{CNF} /$ $\mathrm{RGO} / \mathrm{BC}$ 呈现出优异的比电容 $\left(2588 \mathrm{mF} \cdot \mathrm{cm}^{-2}\right)$ 和循 环稳定性(表 3)。为进一步改善电极性能, $\mathrm{Ma}$ 等 ${ }^{[45]}$ 采用新颖和有效的策略制备 $\mathrm{N}-\mathrm{CNF} / \mathrm{RGO} / \mathrm{BC}$ 柔性 电极, 一步碳化不仅得到 $\mathrm{N}$ 掺杂 $3 \mathrm{D}$ 纳米复合物, 并 且将 $\mathrm{GO}$ 直接还原为高导电 $\mathrm{RGO}$ 。分别以 $\mathrm{KOH}$ 和 $\mathrm{H}_{2} \mathrm{SO}_{4}$ 为电解液组成对称型柔性电容器, 最大能量密
度和功率密度分别可达 $0.11 \mathrm{mWh} \cdot \mathrm{cm}^{-2} / 27 \mathrm{~mW} \cdot \mathrm{cm}^{-2}$ 和 $0.29 \mathrm{mWh} \cdot \mathrm{cm}^{-2} / 37.5 \mathrm{~mW} \cdot \mathrm{cm}^{-2}$ 。其抗拉强度可达 $40.7 \mathrm{MPa}$, 并且弯折不同的角度仍保持良好的电化 学稳定性。 $\mathrm{BC}$ 作为基底所组成的柔性电极对于不 同的碳基活性材料均具有适用性, 且展现出高机械 性能和较好的电化学性能。在发展高性能柔性超级 电容器的研究热潮中极具开发前景。 


\subsection{BC 基噟电容器柔性电极}

目前已开发的柔性电极的制备方法，或工艺繁 琐，或成本高昂，或难规模化应用，不利于之后的 日常应用。基于此，研发简易、低成本、可规模化 生产的柔性电极制备方法成为聚焦热点。将高比电 容的赝电容材料与 $\mathrm{BC}$ 复合成为开发同时具有高电 化学性能和力学性能柔性电极的一种有力手段。

PANI 具有理论容量高、制备方法简单、环境友好及 导电性可控等特点 ${ }^{[46]}$ 。 $\mathrm{Li}_{\text {等 }}^{[1]}$ 以 $\mathrm{BC}$ 为柔性基底, 采 用电化学聚合的方法制备 PANI/CNT/BC 柔性电极。 PANI 均匀地包覆在 CNT/BC 表面(图 6(b)), 三者之 间强的结合力赋予了该复合物电极高的柔性(图 6(a))。 此外, 该电极倍率性能优异(图 6(c))、质量比电容高 和循环稳定性好(表 3)。构建的全固态超级电容器, 如图 6(d) 所示, 可以点亮 LED 灯 (图 6(e)), 将其弯折 成不同的角度，电化学性能无明显变化(图 6(f))。

PPY 是另一种较为重要的导电聚合物, 不仅具有高 导电性、环境友好及高氧化还原特性 ${ }^{[47-48]}$, 而且可 以通过阴离子掺杂拓宽工作窗口从而提高比电容 ${ }^{[49]}$ 。 采用氧化聚合制备的 PPY/BC 电极的电导率和比电 容分别可达到 $3.9 \mathrm{~S} \cdot \mathrm{cm}^{-1}$ 和 $459.5 \mathrm{~F} \cdot \mathrm{g}^{-1}$, 然而循环 50 次后电容保持率仅为 $70.3 \%, 300$ 次后保持在 $21.7 \%$ ，这是由于充放电过程中聚合物的体积发生
了变化 ${ }^{[50-51]}$ 。针对该问题, 引入氧/硫化物制备了多 种三元复合材料, 如 $\mathrm{PPY} / \mathrm{CuS} / \mathrm{BC}^{[52]}$ 、 $\mathrm{PPY} / \mathrm{CoS} /$ $\mathrm{BC}^{[53]}$ 和 $\mathrm{PPY} / \mathrm{NiS} / \mathrm{BC}^{[54]}$ 等, 这些电极的循环稳定性 得到明显改善。Wang 等 ${ }^{[55]}$ 采用化学聚合的方法将 PPY 包覆在 TEMPO 氧化的 BC 纳米纤维上得到 PPY-TOBC 复合膜, 该膜具有较高孔隙率 $\left(101 \mathrm{~m}^{2} \cdot \mathrm{g}^{-1}\right)$ 和电导率 $\left(6.63 \mathrm{~S} \cdot \mathrm{cm}^{-1}\right)$ 。组装的超级电容器的柔性较 高, 最高能量密度为 $6.59 \mathrm{~kW} \cdot \mathrm{kg}^{-1}$, 循环测试发现 其寿命超过 $19 \mathrm{~d}$ 。

$\mathrm{Ma}$ 等 ${ }^{[35]}$ 制备了高导电 $\mathrm{PPY} / \mathrm{BC} / \mathrm{RGO}$ 膜电极, 三者的结合有效缓解了 $\mathrm{RGO}$ 与 $\mathrm{PPY} / \mathrm{BC}$ 的团聚问题, 并为电子和离子的传输提供有效通道。该电极负载 量高达 $13.5 \mathrm{mg} \cdot \mathrm{cm}^{-2}$, 并呈现良好的电化学行为, 可逆的稳定性, 构筑的对称性超级电容器具有较高 的能量密度和功率密度。该策略不仅对于 PPY 是一 种有效的途径, 对其他材料亦具有普适性。PANI/ $\mathrm{BC} / \mathrm{RGO}$ 柔性纸电极 ${ }^{[36]}$ 的负载量为 $12.9 \mathrm{mg} \cdot \mathrm{cm}^{-2}$, 其面积比电容可达到 $6.15 \mathrm{~F} \cdot \mathrm{cm}^{-2}$ 。

前文主要以 $\mathrm{BC}$ 作为 $3 \mathrm{D} \mathrm{CNF}$ 的前驱体 ${ }^{[45]}$ 或支 撑其他功能材料的柔性骨架 ${ }^{[35-56]}$, 接下来 $\mathrm{BC}$ 仅用 作柔性基底制备单侧导电电极 ${ }^{[57]}$ 。将水热和真空过 滤结合制备 $\mathrm{Ni}(\mathrm{OH})_{2} / \mathrm{RGO} / \mathrm{BC}$ 电极, 其中导电 $\mathrm{RGO}$ 包裹的花状 $\mathrm{Ni}(\mathrm{OH})_{2}$ (图 7(a)) 均匀地分散在 $\mathrm{BC} 3 \mathrm{D}$
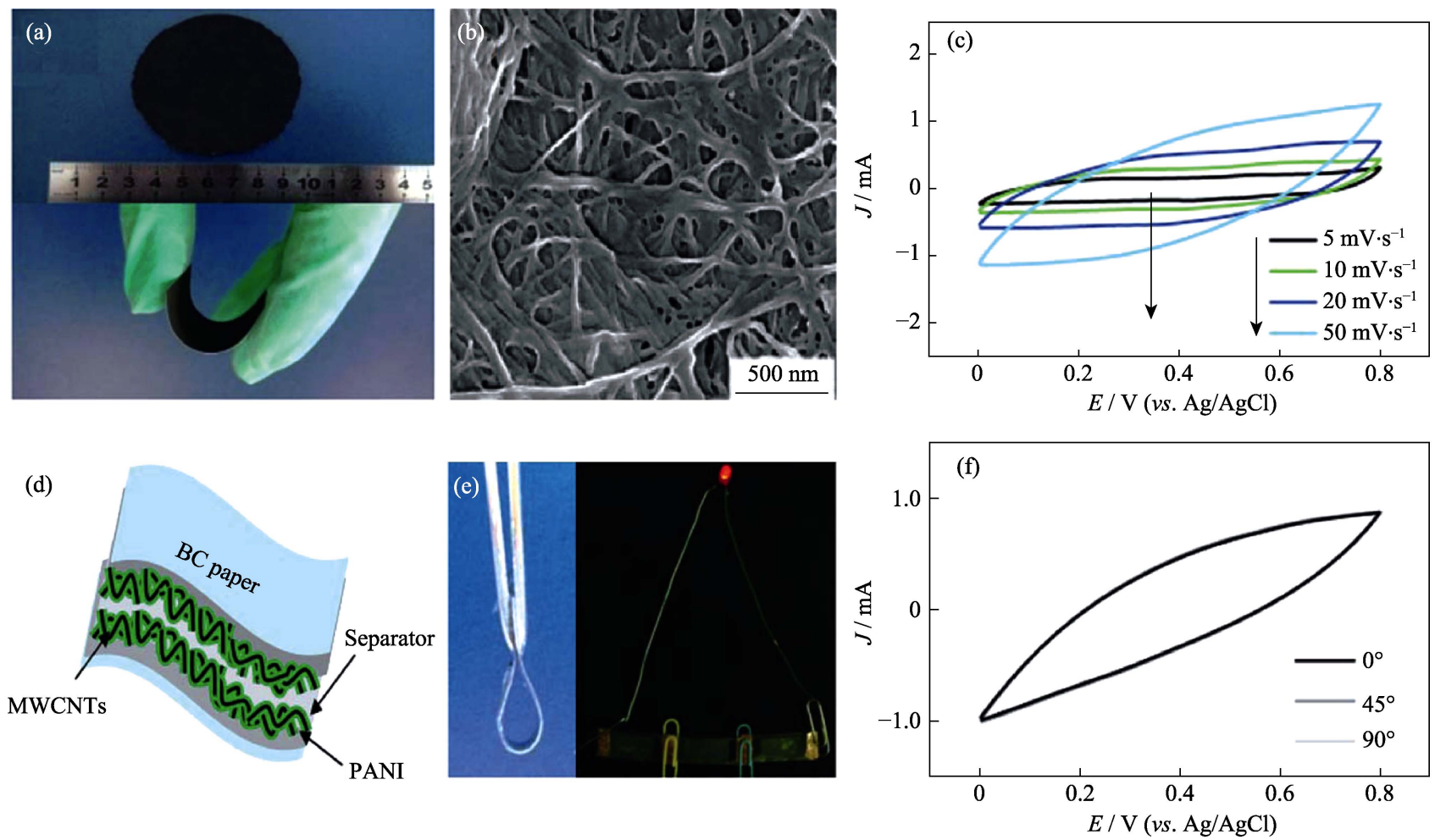

图 6 (a) CNT/BC 和 PANI/CNT/BC 的照片; (b) PANI/CNT/BC 的 SEM 照片和(c) CV 曲线; (d) PANI/CNT/BC 柔性超级电容器的结构示意图, (e)电子照片和(f)不同弯折角度的 CV 曲线 ${ }^{[1]}$

Fig. 6 (a) Photographs of CNT/BC paper and PANI/CNT/BC paper; (b) SEM image and (c) CV curves of PANI/CNT/BC electrode; (d) Schematic structure, (e) digital images and (f) CV curves for flexible supercapacitor ${ }^{[1]}$ 

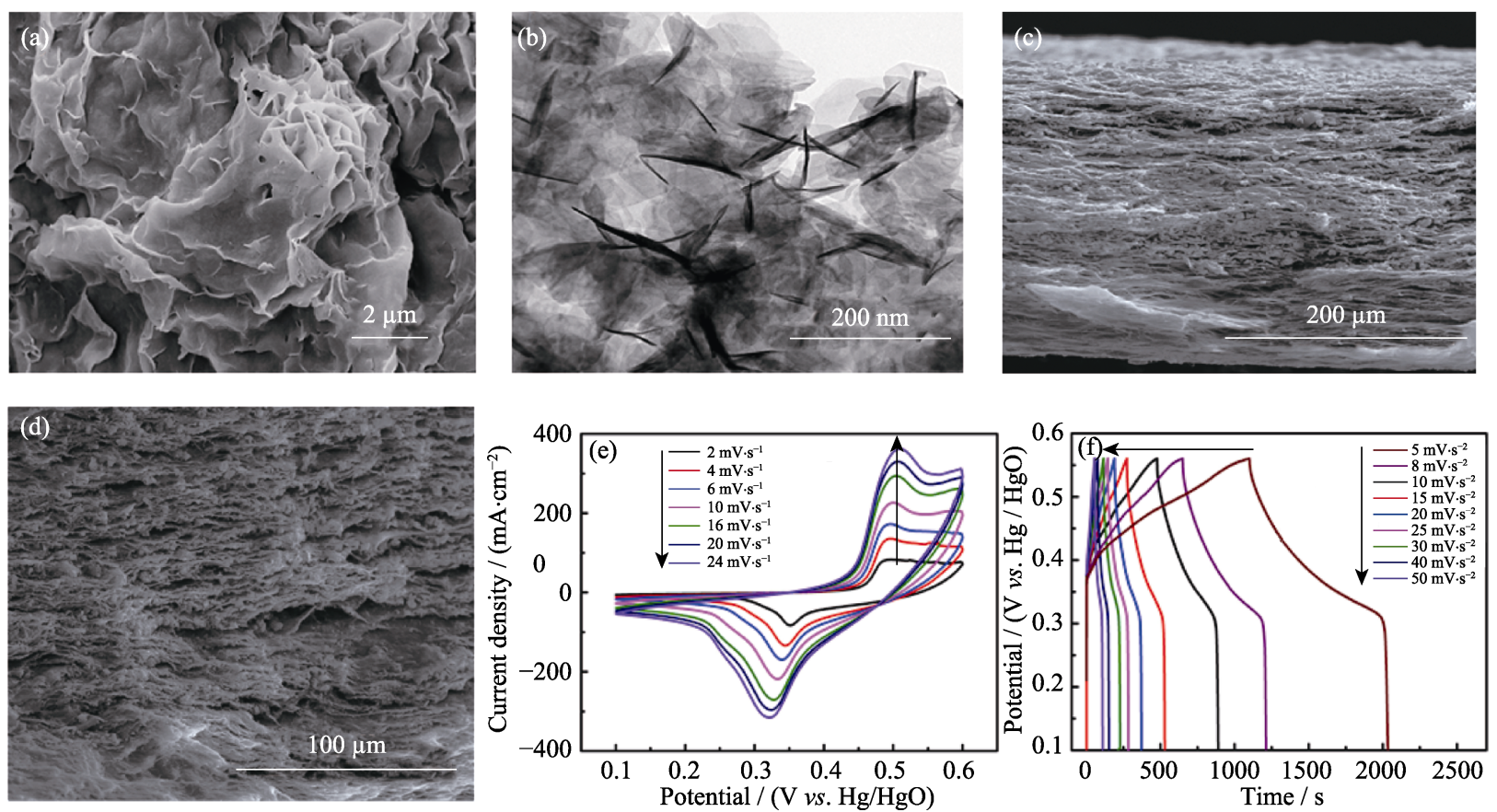

图 $7 \mathrm{Ni}(\mathrm{OH})_{2} / \mathrm{RGO} / \mathrm{BC}$ 的(a)SEM 和(b) TEM 照片; (c,d)Ni(OH) $2 / \mathrm{RGO} / \mathrm{BC}$ 的 $\mathrm{SEM}$ 截面照片; $\mathrm{Ni}(\mathrm{OH})_{2} / \mathrm{RGO} / \mathrm{BC}$ 电极的(e)CV 和(f)GCD 曲线 ${ }^{[58]}$

Fig. 7 (a) SEM and (b) TEM images of $\mathrm{Ni}(\mathrm{OH})_{2} / \mathrm{RGO} / \mathrm{BC}$; (c, d) Cross-sectional SEM micrographs of $\mathrm{Ni}(\mathrm{OH})_{2} / \mathrm{RGO} / \mathrm{BC}$; (e) $\mathrm{CV}$ and (f) $\mathrm{GCD}$ curves of $\mathrm{Ni}(\mathrm{OH})_{2} / \mathrm{RGO} / \mathrm{BC}$ electrode ${ }^{[58]}$

网络中 ${ }^{[58]}$ 。 $\mathrm{RGO}$ 不仅为花状 $\mathrm{Ni}(\mathrm{OH})_{2}$ 提供了生长平 台(图 7(b)), 而且充当缓冲层, 以抑制和吸收充放电 过程中的体积/结构变化。更重要的是, $\mathrm{BC}$ 多孔结构 有利于 $\mathrm{Ni}(\mathrm{OH})_{2} / \mathrm{RGO}$ 进入, 从而保证高质量负载和 良好导电性, 并促进电子传递和离子扩散(图 7(c d ) )。 该电极的负载量高达 $11.9 \mathrm{mg} \cdot \mathrm{cm}^{-2}$, 并展示出优异 的速率和噟电容特性(图 7(e f)), 其面积比电容为 $10.44 \mathrm{~F} \cdot \mathrm{cm}^{-2}$ 。为了验证该方法具有普适性, 进一步 构建了钴基氧化物和氢氧化物电极 ${ }^{[59]}$, 结果表明它 们用于柔性储能装置具有广阔的应用前景。

\section{$2.3 \mathrm{BC}$ 在电解质和隔膜中的应用}

除正/负极外, 隔膜和电解质亦是不可缺少的组 分。隔膜的作用是导通离子而绝缘电子; 电解质存 在于隔膜内部以及活性材料中, 以确保电极之间的 电子/离子传输。电解质的基本要求包括: 高电化学 稳定性、宽电压窗口、低电阻率、高离子浓度、小 溶剂化离子半径、低粘度、低毒性、低挥发性、低 成本以及高纯度的可用性。典型的电解质包括水系 电解液、有机电解液和固态电解液。相比于有机电 解液, 水系电解液具有无毒无害、不可燃、成本低、 对生产环境要求低及离子电导率高等优点, 可极大 改善倍率和快充性能, 获得更高的电容和功率密度, 但是窄的电压窗口(通常低于 $1.2 \mathrm{~V}$ ) 可能限制高能量 密度的实现, 而且作为液体电池其具有诸多不稳定 因素, 存在泄漏和燃烧等安全隐患, 因此非液电解
质越来越受到重视。目前超级电容器中使用最广泛 的是凝胶聚合物，它不仅避免了泄漏问题而且可以 降低封装成本。

Wang 等 ${ }^{[60]}$ 报道了一种新的策略用来构建全生 物材料超级电容器, 主要以热解 $\mathrm{BC}$ 为电极活性材 料, 介电半透明 $\mathrm{BC}$ 基凝胶电解质作为隔膜。其具 有较高的离子迁移率, 比电容为 $289 \mathrm{mF} \cdot \mathrm{cm}^{-2}$, 循环 100 次后电容保持率可达 $66.7 \%$ 。生态友好型全生 物材料超级电容器的概念为高效利用生态友好型生 物材料以及开发用于各种储能器件的新型纳米材料 提供了新的思路。

\section{3 结论与展望}

$\mathrm{BC}$ 以其独特的超细网络结构、高持水性以及优 异的力学性能, 例如耐久性、化学稳定性、机械强 度而受到广泛关注。本文综述了以 $\mathrm{BC}$ 衍生的 $3 \mathrm{D}$ $\mathrm{CNF}$ 纳米材料为电极材料的超级电容器的最新研 究进展。利用杂原子掺杂、金属氧化物纳米粒子修 饰等不同的合成方法, $3 \mathrm{D} \mathrm{CNF}$ 可以转化为高电容复 合电极材料。 $\mathrm{BC}$ 也可以直接作为模板或支架通过 原位聚合或原位生长合成 $\mathrm{BC} /$ 导电聚合物及 $\mathrm{BC} /$ 金 属(氢)氧化物等。此外, 绝缘 $\mathrm{BC}$ 为超级电容器用隔 膜材料提供了绿色来源。柔性超级电容器的最新进 展是出于发现和制造具有实用性能的可穿戴和便携 
式电子器件的愿景。根据相关研究, $\mathrm{BC}$ 可作制备碳 纳米材料、金属氧化物或导电聚合物的基底并具有 普适性, 以确保整个柔性电极的导电性、提供显著 的面积电容、高的质量比电容、优越的倍率性能和 良好的循环稳定性。此外, 绿色可再生并且低成本 的 $\mathrm{BC}$ 可用于制备或支撑其他功能材料, 并且制备 方法简单易行，有利于大规模化生产。

当前, 我国正处在转换经济发展方式、实现新 旧动能转换的关键时期, 促进新能源新材料的不断 发展是坚持创新驱动的必然要求。锂二次电池, 无 论是锂离子电池或锂电池, 均因高能量密度、长循 环寿命、宽温度范围等优点成为当前便携式电子设 备的主要供电单元。为了构筑高性能锂二次电池, 研究人员不断探索、设计和优化各部分部件以满足 更高需求, 或将 $\mathrm{BC}$ 与其他高理论容量活性物质结 合形成兼有协同作用的复合材料; 抑或将其碳化转 为碳材料用于电极材料, 从而创建更加有效的电子 传输路径、促进锂离子的扩散以及改善相应的电化 学性能; 或经细心调控微/纳结构, $\mathrm{BC}$ 膜/纸有望广 泛用于隔膜或电解质。

为了进一步满足当前能源存储设备的需求, 各 种高性能电池横空出世。其中锌一空气电池是以空气 中的氧作为正极, 金属锌为负极, 具有电池容量大、 工作电压平稳、自放电少、安全性高和环境友好等 优点, 有望在信号装置、便携式电池及新能源汽车 等方面得到广泛应用。然而，由于缺乏高效的 ORR 和 OER 催化剂, 其循环寿命较短。而且使用的金属 催化剂如铂和氧化铱等价格昂贵, 储量稀少。以 $\mathrm{BC}$ 为原料制备的 $\mathrm{N}-\mathrm{CNF}$ 气凝胶具有优异的电催化性 能, 可与 $\mathrm{Pt} / \mathrm{C}$ 催化剂相媲美。既有研究成果表明它 在燃料电池和金属一空气电池等研究领域具有潜在 应用前景, 并有望代替 $\mathrm{Pt}$ 基催化剂。所以, $\mathrm{BC}$ 作为 一种极其重要的可再生生物材料, 在锂离子电池、 锂硫电池、锌-空气电池等二次电池中显示出巨大的 潜力，适用于储能领域。

然而, $\mathrm{BC}$ 在各领域得到进一步的广泛应用仍然 存在诸多挑战, $\mathrm{BC}$ 及其复合材料的合理设计和开发 至关重要，还需研究更多的合成策略和开拓更多应 用领域。尽管将噟电容材料与 $\mathrm{BC}$ 基 $\mathrm{CNF}$ 复合成为 前景广阔的功能材料是冊庸置疑的, 但是由于复合 结构中弱的键合力, 界面问题仍然有待解决, 对 $\mathrm{BC}$ 进行功能化处理赋予表面官能团, 通过化学键与电 活性物质连接进而提高其结合力; 同时, BC 用于制 备凝胶电解质及固态电解质的研究较少, 开发及构 筑高性能新型固态电池/固态超级电容器的隔膜或
固态电解质也是方兴未艾。相信下一步这一研究领 域会吸引更多研究者的注意，成为热点领域。

\section{参考文献:}

[1] LI S H, HUANG D K, ZHANG B Y, et al. Flexible supercapacitors based on bacterial cellulose paper electrodes. Adv. Energy Mater. 2014, 4(10): 1301655.

[2] CHEN L F, HUANG Z H, LIANG H W, et al. Three-dimensional heteroatom-doped carbon nanofiber networks derived from bacterial cellulose for supercapacitors. Adv. Funct. Mater., 2014, 24(32): 5104-5111.

[3] WU Z Y, LIANG H W, CHEN L F, et al. Bacterial cellulose: a robust platform for design of three dimensional carbon-based functional nanomaterials. Acc. Chem. Res., 2016, 49(1): 96-105.

[4] MA L N, LIU R, NIU H J, et al. Flexible and freestanding electrode based on polypyrrole/graphene/bacterial cellulose paper for supercapacitor. Compos. Sci. Technol., 2016, 137(12): 87-93.

[5] IGUCHI M, YAMANAKA S, BUDHIOKO A. Bacterial cellulosea masterpiece of nature's arts. J. Mater. Sci., 2000, 35(2): 261-270.

[6] TIAN X D, LI X, YANG T, et al. Recent advances on synthesis and supercapacitor application of binary metal oxide. J. Inorg. Mater., 2017, 32(5): 459-468.

[7] ZENG Y F, XIN G X, BU L C K et al. One-step preparation and electrochemical performance of 3D reduced graphene oxide $/ \mathrm{NiO}$ as supercapacitor electrodes materials. J. Inorg. Mater, 2018, 33(10): 1070-1076.

[8] QU L, PEI H M, KONG R M, et al. Novel turn-on fluorescent detection of alkaline phosphatase based on green synthesized carbon dots and $\mathrm{MnO}_{2}$ nanosheets. Talanta, 2017, 165: 136-142.

[9] ZHAO J, GONG X B, ZHANG R M, et al. Enhanced biosensing platform constructed using urchin-like ZnO-Au@CdS microspheres based on the combination of photoelectrochemical and bioetching strategies. Sens. Actuators B: Chem., 2018, 255: 1753-1761.

[10] YAO J J, JI P, NAN SHENG N, et al. Hierarchical core-sheath polypyrrole@carbon nanotube/bacterial cellulose macrofibers with high electrochemical performance for allsolid-state supercapacitors Electrochim. Acta, 2018, 283: 1578-1588.

[11] LI J, ZHANG G F, CHEN N, et al. Built structure of ordered vertically aligned codoped carbon nanowire arrays for supercapacitors. ACS Appl. Mater. Interfaces, 2017, 9: 24840-24845.

[12] LONG C L, QI D P, WEI T, et al. Nitrogen-doped carbon networks for high energy density supercapacitors derived from polyaniline coated bacterial cellulose. Adv. Funct. Mater, 2014, 24(25): 3953-3961.

[13] LEI W, HAN L L, XUAN C J, et al. Nitrogen-doped carbon nanofibers derived from polypyrrole coated bacterial cellulose as high-performance electrode materials for supercapacitors and Li-ion batteries. Electrochim. Acta, 2016, 210: 130-137.

[14] LEE K Y, QIAN H, TAY F H, et al. Bacterial cellulose as source for activated nanosized carbon for electric double layer capacitors. J. Mater. Sci., 2013, 48(1): 367-376.

[15] YU W D, LIN W R, SHAO X F, et al. High performance supercapacitor based on $\mathrm{Ni}_{3} \mathrm{~S}_{2} /$ carbon nanofibers and carbon nanofibers electrodes derived from bacterial cellulose. J. Power Sour., 2014, 272: $137-143$

[16] LIU R, MA L N, MEI J, et al. Large areal mass, mechanically tough and freestanding electrode based on heteroatom-doped carbon nanofibers for flexible supercapacitors. Chem-Eur. J., 2017, 23(11): 2610-2618.

[17] YUAN D, HUANG X, YAN J, et al. Porous carbon nanofibers de- 
rived from bacterial cellulose for sustainable energy storage. Science of Advanced Materials, 2013, 5(11): 1694-1700.

[18] JIANG Y T, YAN J, WU X L, et al. Facile synthesis of carbon nanofibers-bridged porous carbon nanosheets for high-performance supercapacitors. J. Power Sour, 2016, 307: 190-198.

[19] LAI F L, MIAO Y E, ZUO L Z, et al. Carbon aerogels derived from bacterial cellulose/polyimide composites as versatile adsorbents and supercapacitor electrodes. ChemNanoMat, 2016, 2(3): $212-219$.

[20] WU Z Y, LIANG H W, LI C, et al. Dyeing bacterial cellulose pellicles for energetic heteroatom doped carbon nanofiber aerogel. Nano Res., 2014, 7(12): 1861-1872.

[21] LUO H L, DONG J J, ZHANG Y, et al. Constructing 3D bacterial cellulose/graphene/polyaniline nanocomposites by novel layer-bylayer in situ culture toward mechanically robust and highly flexible freestanding electrodes for supercapacitors. Chem. Eng. J., 2018, 334: $1148-1158$.

[22] WU H, ZHANG Y Z, YUAN W Y, et al. Highly flexible, foldable and stretchable Ni-Co layered double hydroxide/polyaniline/bacterial cellulose electrodes for high performance all-solid-state supercapacitors. J. Mater. Chem. A, 2018, 6(34): 16617-16626.

[23] LAI F L, MIAO Y, ZUO L Z, et al. Biomass-derived nitrogendoped carbon nanofiber network: a facile template for decoration of ultrathin nickel-cobalt layered double hydroxide nanosheets as high-performance asymmetric supercapacitor electrode. Small, 2016, 12(24): 3235-3244.

[24] CHEN L F, HUANG Z H, LIANG H W, et al. Bacterial-cellulosederived carbon nanofiber@ $\mathrm{MnO}_{2}$ and nitrogen-doped carbon nanofiber electrode materials: an asymmetric supercapacitor with high energy and power density. Adv. Mater, 2013, 25(34): 4746-4752.

[25] CHEN L F, HUANG Z H, LIANG H W, et al. Flexible all-solid-state high-power supercapacitor fabricated with nitrogendoped carbon nanofiber electrode material derived from bacterial cellulose. Energy Environ. Sci., 2013, 6(11): 3331-3338.

[26] HU Z X, LI S S, CHENG P P, et al. N,P-co-doped carbon nanowires prepared from bacterial cellulose for supercapacitor. $J$. Mater. Sci., 2016, 51(5): 2627-2633.

[27] LI S M, YANG S Y, WANG Y S, et al. N-doped structures and surface functional groups of reduced graphene oxide and their effect on the electrochemical performance of supercapacitor with organic electrolyte. J. Power Sources, 2015, 278: 218-229.

[28] ZHAO L, HU Y S, LI H, et al. Porous $\mathrm{Li}_{4} \mathrm{Ti}_{5} \mathrm{O}_{12}$ coated with $\mathrm{N}$-doped carbon from ionic liquids for Li-Ion batteries. Advanced Materials, 2011, 23(11): 1385-1388.

[29] HAO L, LUO B, LI X, et al. Terephthalonitrile-derived nitrogenrich networks for high performance supercapacitors. Energy \& Environmental Science, 2012, 5(12): 9747-9751.

[30] LIU Y Q, YAN Y, LI K, et al. A high-areal-capacity lithium-sulfur cathode achieved by a boron-doped carbon-sulfur aerogel with consecutive core-shell structures. Chem. Commun., 2019, 55(8): 1084-1087.

[31] DING L G, YAO B J, LI F, et al. Ionic liquid-decorated COF and its covalent composite aerogel for selective $\mathrm{CO}_{2}$ adsorption and catalytic conversion. J. Mater. Chem. A, 2019, DOI: 10.1039/ C8TA12046C.

[32] LIN C, HUANG Q, ZHANG D, et al. Temperature programmed surface reaction test of $\mathrm{Co}-\mathrm{Ni}$ bimetallic aerogel catalysts for methane reforming. React. Kinet. Mech. Cat., 2019, DOI: 10.1007/ s11144-018-01531-3.

[33] GIGOT A, FONTANA M, PIRRI C F, et al. Graphene/ruthenium active species aerogel as electrode for supercapacitor applications. Materials, 2018, 11(1): 57.
[34] XU X Z, ZHOU J, NAGARAJU D H, et al. Flexible, highly graphitized carbon aerogels based on bacterial cellulose/lignin: catalyst-free synthesis and its application in energy storage devices. Adv. Funct. Mater., 2015, 25(21): 3193-3202.

[35] MA L N, LIU R, NIU H J, et al. Freestanding conductive film based on polypyrrole/bacterial cellulose/graphene paper for flexible supercapacitor: large areal mass exhibits excellent areal capacitance. Electrochim. Acta, 2016, 222(20): 429-437.

[36] LIU R, MA L N, HUANG S, et al. Large areal mass, flexible and freestanding polyaniline/bacterial cellulose/graphene film for highperformance supercapacitors. RSC Adv., 2016, 6(109): 107426-107432.

[37] MULlER D, RECOUVREUX D O S, PORTO L M, et al. Chemical in situ polymerization of polypyrrole on bacterial cellulose nanofibers. Synthetic Met., 2011, 161(1/2): 106-111.

[38] LIU Y, ZHOU J, TANG J, et al. Three-dimensional, chemically bonded polypyrrole/bacterial cellulose/graphene composites for highperformance supercapacitors. Chem. Mater, 2015, 27(20): 7034-7041.

[39] WU H, HUANG Y A, XU F, et al. Energy harvesters for wearable and stretchable electronics: from flexibility to stretchability. $A d v$. Mater, 2016, 28(45): 9881-9919.

[40] ZHENG Y, YANG Y B, CHEN S S, et al. Smart, stretchable and wearable supercapacitors: prospects and challenges. CrystEngComm, 2016, 18(23): 4218-4235.

[41] KANG Y J, CHUN S J, LEE S S, et al. All-solid-state flexible supercapacitors fabricated with bacterial nanocellulose papers, carbon nanotubes, and triblock-copolymer ion gels. ACS Nano, 2012, 6(7): 6400-6406.

[42] SUMBOJA A, FOO C Y, WANG X, et al. Large areal mass, flexible and free-standing reduced graphene oxide/manganese dioxide paper for asymmetric supercapacitor device. Adv. Mater, 2013, 25(20): 2809-2815.

[43] XIONG Z Y, LIAO C L, HAN W H, et al. Mechanically tough large-area hierarchical porous graphene films for high-performance flexible supercapacitor applications. Adv. Mater, 2015, 27(30): 4469-4475.

[44] LIU Y, ZHOU J, ZHU E W, et al. Facile synthesis of bacterial cellulose fibres covalently intercalated with graphene oxide by onestep cross-linking for robust supercapacitors. J. Mater. Chem. C, 2015, 3(5): 1011-1017.

[45] MA L N, LIU R, NIU, H J, et al. Flexible and freestanding supercapacitor electrodes based on nitrogen-doped carbon networks/ graphene/bacterial cellulose with ultrahigh areal capacitance. ACS Appl. Mater. Interfaces, 2016, 8(49): 33608-33618.

[46] XIA C, CHEN W, WANG X B, et al. Highly stable supercapacitors with conducting polymer core-shell electrodes for energy storage applications. Adv. Energy Mater., 2015, 5(8): 1401805.

[47] YANG C Y, SHEN J L, WANG C Y, et al. All-solid-state asymmetric supercapacitor based on reduced graphene oxide/carbon nanotube and carbon fiber paper/polypyrrole electrodes. J. Mater. Chem. A, 2014, 2(5): 1458-1464.

[48] ZHAO Y, LIU J, HU Y, et al. Highly compression-tolerant supercapacitor based on polypyrrole-mediated graphene foam electrodes. Adv. Mater., 2013, 25(4): 591-595.

[49] SONG Y, XU J L, LIU X X. Electrochemical anchoring of dual doping polypyrrole on graphene sheets partially exfoliated from graphite foil for high-performance supercapacitor electrode. $J$. Power Sour., 2014, 249: 48-58.

[50] LEE H J, CHUANG T J, KWON H J, et al. Fabrication and evaluation of bacterial cellulose-polyaniline composites by interfacial polymerization. Cellulose, 2012, 19: 1251-1258.

[51] XU J, ZHU L G, BAI Z K, et al. Conductive polypyrrole-bacterial cellulose nanocomposite membranes as flexible supercapacitor 
electrode. Org. Electron., 2013, 14(12): 3331-3338.

[52] PENG S, FAN L L, WEI C Z, et al. Flexible polypyrrole/copper sulfide/bacterial cellulose nanofibrous composite membranes as supercapacitor electrodes. Carbohyd. Polym., 2017, 157: 344-352.

[53] PENG S, XU Q, FAN L L, et al. Flexible polypyrrole/cobalt sulfide/ bacterial cellulose composite membranes for supercapacitor application. Synthetic Met., 2016, 222: 285-292.

[54] PENG S, FAN L L, WEI C Z, et al. Polypyrrole/nickel sulfide/ bacterial cellulose nanofibrous composite membranes for flexible supercapacitor electrodes. Cellulose, 2016, 23(4): 2639-2651.

[55] WANG F, KIM H J, PARK S, et al. Bendable and flexible supercapacitor based on polypyrrole-coated bacterial cellulose core-shell composite network. Compos. Sci. Technol., 2016, 128(18): 33-40.

[56] YUAN L, YAO B, HU B, et al. Polypyrrole-coated paper for flexible solid-state energy storage. Energy Environ. Sci., 2013, 6(2):
6(2): 470-476.

[57] LIU R, MA L N, HUANG S, et al. A flexible polyaniline/ graphene/bacterial cellulose supercapacitor electrode. New J. Chem., 2017, 41(2): 857-864.

[58] MA L N, LIU R, WANG, F, et al. Facile synthesis of $\mathrm{Ni}(\mathrm{OH})_{2}$ /graphene/bacterial cellulose paper for large areal mass, mechanically tough and flexible supercapacitor electrodes. $J$. Power Sour, 2016, 335(15): 76-83.

[59] LIU R, MA L N, HUANG S, et al. Large areal mass and high scalable and flexible cobalt oxide/graphene/bacterial cellulose electrode for supercapacitors. J. Phys. Chem. C, 2016, 120(50): 28480-28488.

[60] WANG X, KONG D, ZHANG Y, et al. All-biomaterial supercapacitor derived from bacterial cellulose. Nanoscale, 2016, 8(17): 9146-9150. 